\title{
How macrophages respond to two-dimensional materials: a critical overview
} focusing on toxicity

\author{
Hazel Lin, Zhengmei Song, Alberto Bianco ${ }^{1}$ \\ ${ }^{1}$ CNRS, Immunology, Immunopathology and Therapeutic Chemistry, UPR 3572, \\ University of Strasbourg, ISIS, 67000 Strasbourg, France \\ *Corresponding author: Alberto Bianco \\ E-mail: a.bianco@ibmc-cnrs.unistra.fr
}

With wider use of graphene-based materials and other two-dimensional (2D) materials in various fields, including electronics, composites, biomedicine, etc., 2D materials can trigger undesired effects at cellular, tissue and organ level. Macrophages can be found in many organs. They are one of the most important cells in the immune system and they are relevant in the study of nanomaterials as they phagocytose them. Nanomaterials have multi-faceted effects on phagocytic immune cells like macrophages, showing signs of inflammation in the form of pro-inflammatory cytokine or reactive oxidation species production, or upregulation of activation markers due to the presence of these foreign bodies. This review is catered to researchers interested in the potential impact and toxicity of 2D materials, particularly in macrophages, focusing on few-layer graphene, graphene oxide, graphene quantum dots, as well as other promising 2D materials containing molybdenum, manganese, boron, phosphorus and tungsten. We describe applications relevant to the growing area of $2 \mathrm{D}$ materials research, and the possible risks of ions and molecules used in the production of these promising 2D materials, or those produced by the degradation and dissolution of 2D materials.

Keywords: Immune cells; graphene; molybdenum; manganese; boron; nanomaterials; 2D materials; cytokines; phosphorus; tungsten 


\section{Introduction}

2 The immune system comprises of mainly two groups of cells: lymphocytes and myeloid

3 cells. Lymphocytes can be subdivided into B cells, T cells, natural killer (NK) cells, and

4 NK-T cells. Myeloid cells can be subdivided into platelets, erythrocytes, and cells of the

5 granulocyte lineage such as neutrophils, monocytes, macrophages, eosinophils,

6 basophils, and mast cells. ${ }^{[1]}$ Neutrophils and monocytes are the most prominent

7 phagocytes in the blood and are the body's first defense against foreign organisms or

8 materials, while macrophages are the main immune cells which process nanoparticles.

9 These phagocytes are therefore more relevant to immune cell interaction with $2 \mathrm{D}$

10 materials. ${ }^{[2,3]}$ Of these, macrophages have a longer lifespan and are mostly used in in

11 vitro studies.

12 Macrophages can be found in all tissues of the body and are fundamental in host defence.

13 They phagocytose dead cells and debris, shape inflammatory response and modulate

14 adaptive immunity. ${ }^{[4]}$ Macrophages are one of the first cells which encounter

15 nanomaterials, and promptly produce pro-inflammatory cytokines such as IL-6 and TNF-

$16 \alpha$ to initiate a down-stream immune response upon foreign particle recognition. [5]

17 Macrophages also secrete anti-bacterial and proteolytic enzymes, chemokines, and anti-

18 inflammatory cytokines, such as IL-10 and TGF- $\beta$, and produce reactive oxidative species

19 (ROS), nitrogen, and arachidonate metabolites. ${ }^{[6]}$

20 Although macrophages are able to recognize and internalize nanomaterials, it is generally

21 unknown how exactly nanoparticle recognition occurs, with respect to specific cell-

22 surface receptors and membrane cholesterol. ${ }^{[7]}$ Nanomaterials interact with the biological

23 molecules by coating their surface and forming the protein corona. ${ }^{[8]}$ In fact, the protein

24 corona dictates nanoparticle interaction with macrophages through mediation of 
1 recognition and uptake into these cells. ${ }^{[9]}$ Nanoparticle-macrophage interactions are also

2 dependent on particle properties, physicochemical characteristics such as size, shape,

3 charge, and colloidal stability. As a rough guide, small positively charged nanoparticles

4 are in general more toxic than big negatively charged ones. ${ }^{[10]}$

5 The nanoparticles have the potential to affect macrophage polarization, and therefore 6 internalization. Macrophage polarization is an activation process following micro7 environmental signals. At the end of this process, macrophage phenotypes can be 8 categorized into two groups: 1) pro-inflammatory M1, and 2) anti-inflammatory M2. 9 Polyurethane nanoparticles were found to inhibit polarization toward M1 phenotype but 10 not M2, decreasing production of M1 cytokines TNF- $\alpha$ and IL-1 $\beta$. [11] Silicon 11 nanoparticles were found to have higher uptake in M1 compared to M2 RAW 264.7 12 macrophages, ${ }^{[12]}$ although contradictory results were observed in another study using 13 primary human macrophages. ${ }^{[13]}$

14 The nanoparticle exposure at subtoxic concentrations can result in ROS production, increased secretion of pro-inflammatory cytokines and upregulation of activation markers

16 in macrophages. ${ }^{[14]}$ At higher concentrations or in certain experimental conditions, 17 nanoparticles can exert macrophage toxicity in various ways, which may or may not be 18 indirectly linked, such as endoplasmic reticulum stress, ${ }^{[15]}$ autophagic cell death, ${ }^{[16]}$ 19 mitochondrial dysfunction, ${ }^{[17]}$ lysosomal dysfunction ${ }^{[18]}$ or oxidative damage. ${ }^{[19]}$ ROS 20 in particular can be highly relevant in genotoxicity, which may be related to nanoparticle 21 surface properties, presence of transition metals, intracellular iron mobilization, particle 22 uptake, interaction and lipid peroxidation. ${ }^{[20]}$

23 The class of 2D nanomaterials covers many types of materials, including monolayered 24 elements going from graphene and phosphorene (also known as black phosphorus) to 
1 dichalcogenides to layered silicate minerals. ${ }^{[21]}$ Graphene safety has been extensively

2 reviewed in many cell types, including macrophages. ${ }^{[22]}$ Nitrides such as hexagonal

3 boron nitride (hBN), an isomorph of graphene, and transition metal dichalcogenides such

4 as molybdenum disulfide, tungsten disulfide, hold much promise in the semiconductor

5 industry. ${ }^{[23]}$ (Fig.1) 2D nanomaterials have also vast potential for use in electronics,

6 sensing, spintronics, photonics, thermoelectrics and energy systems. ${ }^{[24]}$ They have been

7 explored in biomedicine, for example in bioimaging, cancer theranostics, biosensing and

8 antimicrobials, although little is still known about their toxicity. ${ }^{[25]}$

9 Given the potential to synergise their unique benefits in the 2D structure, there have been

10 several combinations involving $2 \mathrm{D}$ nanomaterials in fields ranging from electronics to

11 oncology. Boron has versatile bonding configurations and can intercalate with graphene

12 despite a crystallographic lattice and symmetry mismatch. ${ }^{[26]}$ Boron-doped graphene

13 nanoribbons, [27] boron-doped nanographene and boron-doped graphene- $\mathrm{MoS}_{2}$

14 nanohybrids ${ }^{[28]}$ have also emerged in the battery and semi-conductor industry. ${ }^{[29]}$ Black

15 phosphorus- $\mathrm{MoS}_{2}$ nanocomposites have been utilized in dye decomposition, ${ }^{[30]}$ while

16 black phosphorus-hBN-rhenium diselenide heterojunction diodes have found use in

17 electronics. ${ }^{[31]}$

18 In biology and chemistry, tungsten-doped manganese dioxide has been reported to be

19 exploited in formaldehyde removal, ${ }^{[32]}$ while a black phosphorus-manganese dioxide

20 nanoplatform has been used in oxygen monitoring and in photodynamic therapy. ${ }^{[33]}$

$21 \mathrm{MoS}_{2}$-graphene oxide (GO) nanocomposites have shown efficacy in lung cancer therapy

$22{ }^{[34]}$ and GO nanosheets decorated with copper oxide- $\mathrm{WO}_{3}$ nanoparticles were used to

23 detect cancer cells. ${ }^{[35]}$ 
1 In this review, we will focus on the impact of the most representative groups of 2D

2 nanomaterials on macrophages. Quantum dots and nanoparticles have been included as

3 well, as they are considered a subset of 2D materials, as seen in many recent publications

4 reporting production methods reminiscent of $2 \mathrm{D}$ materials and resultant $2 \mathrm{D}$ properties.

$5^{[36-38]}$ We will describe the effects of graphene, as sub-divided into few-layer graphene

6 (FLG), GO and graphene quantum dots (GQDs). We will also cover $\mathrm{MoS}_{2}$ and other

7 forms of molybdenum, $\mathrm{MnO}_{2}$ and other forms of manganese, $\mathrm{hBN}$ and other forms of

8 boron, black phosphorus, tungsten trioxide and other forms of tungsten. The scope for

9 upcoming and less explored non-graphene 2D materials includes other forms of the same

10 element and non-macrophage cells to provide a clearer picture of elemental and molecular

11 toxicity. This will hopefully enable the reader to better understand the predicted

12 macrophage toxicity of these new materials.

\section{Graphene}

14 Graphene, the first true 2D crystalline material, was isolated by Geim and Novoselov in 15 2004. ${ }^{[39]}$ Graphene consists of single layer sp $^{2}$-hybridized carbon atoms arranged in a 16 hexagonal lattice, with a carbon-carbon distance of $1.42 \AA$. The large $\pi$ conjugation in 17 graphene results in its exceptional electrical, thermal, optical, and mechanical properties.

18 These properties can be altered as well by appropriate chemical modifications. The 19 graphene family is huge and includes FLG, GO and GQDs (Fig.2), which we will cover 20 in this review. Due to their physicochemical properties, graphene family nanomaterials 21 have attracted considerable attention in a myriad of fields ${ }^{[40]}$ such as biomedicine, ${ }^{[41]}$ 22 electronics, ${ }^{[42]}$ photonics, ${ }^{[43,44]}$ composite materials, ${ }^{[45]}$ sensors and metrology. ${ }^{[46]}$ In 23 view of the broad spectrum of applications and the increasing use of graphene family 24 nanomaterials in different industrial sectors, it is crucial to understand their impact on 
1 cells and tissues, especially the interactions with the immune system and in particular in

2 macrophages. ${ }^{[47]}$ In this section, we discuss in detail the effects of FLG, GO and GQDs

3 on macrophages. ${ }^{[21]}$

\section{$4 \quad$ Few-layer graphene}

$5 \quad$ FLG refers to graphene materials with less than 4-10 layers of nanosheets, ${ }^{[48]}$ When the

6 number of atomic layers increases, the material becomes more metallic ${ }^{[49]}$ and the

7 thermal conductivity decreases. ${ }^{[50]}$ FLG is gaining importance in fields like

8 nanomedicine, because it is much easier to obtain high quantities and its colloidal

9 properties are still maintained in biological media. ${ }^{[51]}$ In this context it is important to

10 consider the effects of FLG on macrophages.

11 It has been demonstrated that FLG is able to induce cytotoxicity in RAW 264.7

12 macrophages by decreasing mitochondrial membrane potential (MMP), causing the

13 accumulation of intracellular ROS, and triggering apoptosis through activation of the

14 mitochondrial pathway. The mitogen-associated protein kinases (MAPKs) and TGF- $\beta$ -

15 related signaling pathways may also be involved. ${ }^{[52]}$ It was observed that pristine

16 graphene nanosheets produce holes in the membranes of RAW 264.7 macrophages,

17 reducing cell viability. This was due to strong interactions between pristine graphene and

18 membrane phospholipid tails. ${ }^{[53]}$ It was also reported that FLG could stimulate the

19 secretion of cytokines like IL-1 $\alpha$, IL-6, IL-10, TNF- $\alpha$ and GM-CSF and chemokines such

20 as MCP-1, MIP-1a, MIP-1b and RANTES on both primary murine macrophages and

21 immortalized macrophages. This effect was linked to the toll-like receptor (TLR)-

22 mediated and NF- $\kappa$ B pathways. ${ }^{[54]}$ Our group however, showed that primary human M1

23 and M2 macrophage viability and activation were mainly found to be unaffected by $24 \mathrm{~h}$

24 treatment with FLG at doses up to $50 \mu \mathrm{g} / \mathrm{mL} .{ }^{[55]} \mathrm{We}$ also found high cell viability of 
1 RAW 264.7 cells after exposure to FLG for $24 \mathrm{~h}$ and no in vivo hematotoxicity in Balb/c

2 mice at $300 \mu \mathrm{g} / \mathrm{mouse}$ up to 30 days. ${ }^{[56]}$

3 Recently, Cristo et al. presented the detailed toxicity mechanism of low-dose (2.5 and 5

$4 \mu \mathrm{g} / \mathrm{cm}^{2}$ ) of $265 \mathrm{~nm}$ FLG in RAW 264.7 macrophages. The results of this study revealed

5 that FLG induced inflammation by oxidative stress, triggering endoplasmic reticulum

6 stress-mediated autophagy. ${ }^{[57]}$ On the contrary, our group reported that FLG of 100-1600

$7 \mathrm{~nm}$ lateral size did not induce inflammatory responses nor cell toxicity in mouse primary

8 bone marrow-derived macrophages. The cellular stress and the basal level of autophagic

9 activity were not affected at any dose of FLG $(3-100 \mu \mathrm{g} / \mathrm{mL}) .{ }^{[58]}$ The study showed that

10 the material was internalized mainly through phagocytosis and partly by passive

11 diffusion. No significant increased secretion of inflammation-related cytokines such as

12 IL-1 $\beta$, IL-6 and TNF- $\alpha$ was observed. The results are in agreement with another work,

$13{ }^{[59]}$ where pristine graphene did not induce autophagy after being phagocytosed by human

14 primary macrophages (from peripheral blood mononuclear cells, PBMCs). Similarly, it

15 was demonstrated that pristine graphene cannot induce immune stimulation and toxic

16 effects in vitro. ${ }^{[60]}$ In another study, ${ }^{[61]}$ pristine graphene nanosheets stabilized by flavin

17 mononucleotide of two different sizes (PG-FMN, 200-400 nm and 100-200 nm) enhanced

18 the release of nitric oxide with metabolic alterations. Interestingly, the smaller PG-FMN

19 increased the levels of succinate, itaconate, phosphocholine in RAW 264.7 macrophage,

20 which was not observed in cells incubated with larger PG-FMN nanosheets.

21 Other studies compared the toxicity and cellular uptake of FLG and functionalized FLG.

$22[62,63]$ The interaction of pristine graphene (corresponding to FLG) and carboxyl-

23 functionalized graphene (FLG-COOH) in RAW 264.7 macrophages and PBMCs showed

24 relatively high intracellular uptake of FLG-COOH compared to FLG, which was found 
1 to be mainly retained on the cell surface and induced stress effects above $50 \mu \mathrm{g} / \mathrm{mL}$

2 through the induction of ROS-mediated apoptosis. In contrast, the FLG-COOH rendered

3 better cytocompatibility with no stress effects up to $75 \mu \mathrm{g} / \mathrm{mL}$. Studies focusing on pro-

4 inflammatory cytokine expression (e.g., IL-1 $\beta$, IL-6, IL-8, IL-10, TNF- $\alpha$, and IL-12p70)

5 showed that FLG-treated PBMCs expressed relatively higher levels of IL-8 and IL-6

6 compared to FLG-COOH samples, thus indicating the inflammatory potential of the

7 former. ${ }^{[63]}$ These results demonstrated that highly hydrophobic pristine graphene was

8 more toxic than hydrophilic, functionalized graphene.

9 Biodegradation is important during the study of biomedical applications, to ascertain

10 eventual material safety within the body. Aggregates $(60 \mu \mathrm{g} / \mathrm{mL})$ of phagocytosed

11 pristine graphene (200 nm lateral size) were found in RAW 264.7 macrophages within

$1224 \mathrm{~h}$ as observed by confocal Raman spectroscopy. Macrophage-engulfed graphene was

13 shown to result in time-dependent degraded material reiterating the role of macrophages

14 in biodegradation. (Fig.3) ${ }^{[64]}$ The same group also compared the 3-month toxicity, organ

15 biodistribution and immune response of FLG, FLG-COOH and FLG-PEG of 100-200 nm

16 in Swiss albino mice at $20 \mathrm{mg} / \mathrm{kg}$. The results showed that all the materials were mostly

17 retained in the lung, spleen and liver, with FLG and FLG-COOH inducing significant

18 cellular and structural damages to lungs, liver, spleen, and kidney. In contrast, FLG-PEG-

19 administered animals showed no significant abnormalities and normal biochemical

20 markers. In addition, FLG-PEG evidenced clear signs of biodegradation using Raman

21 confocal imaging. ${ }^{[65]}$

22 Overall, FLG could decrease cell viability, damage cell membrane, induce apoptosis and

23 increase cytokine production in macrophages, with the main mechanism of cytotoxicity

24 related to MMP reduction and ROS increase. Addition of functional groups on the surface 
1 of FLG can modulate cytotoxicity. As FLG is easily taken up by macrophages and widely

2 used in biomedicine, future studies could be focused on in vitro and in vivo

3 biodegradation of FLG, a neglected area of research.

\section{$4 \quad$ Graphene oxide}

5 GO is the oxidized form of graphene. It is made of 2D carbon obtained from graphite

6 sheets under strong acid conditions, which thereby introduces oxygenated groups onto

7 carbon-carbon double bonds. ${ }^{[66-68]}$ On the surface of GO we can identify mainly hydroxyl

8 and epoxy groups, while at the edges there are few carboxylic and carbonyl functions.

9 The presence of these groups accounts for a high hydrophilicity, a superior water 10 dispersibility, a good colloidal stability and an easy surface functionalization. Owning to

11 these properties, GO is currently the most widely investigated graphene family materials

12 for biology-related applications, ${ }^{[69,70]}$ including drug delivery, ${ }^{[71,72]}$ cancer therapy and

13 viral infections, ${ }^{[73]}$ tissue engineering, ${ }^{[74]}$ bioimaging ${ }^{[75]}$ and biosensing. ${ }^{[76]}$ Here, we

14 present a summary of the research efforts to elucidate the bioeffects of GO on 15 macrophages including cytotoxicity, cellular uptake, inflammatory effects and 16 macrophage polarization.

\section{Cytotoxicity studies in macrophages}

18 Many studies revealed that GO can damage the membrane and cytoskeleton of 19 macrophages. For instance, single-layer GO nanosheets with a lateral size ranging from $20200 \mathrm{~nm}$ to $700 \mathrm{~nm}$ can reduce cell viability by producing holes in the membranes of RAW 21264.7 macrophages. ${ }^{[53]}$ Similarly, monolayer GO within the range of 100-300 nm 22 provoked plasma membrane and cytoskeleton damage in J774A.1 macrophages at 23 sublethal concentrations $(20 \mu \mathrm{g} / \mathrm{mL})$ without inducing significant cell death. The 24 interactions of GO with membrane integrin was found to activate the integrin-FAK-Rho- 
1 ROCK pathway and to suppress the expression of integrin, resulting in a compromised

2 cell membrane and cytoskeleton. ${ }^{[77]}$

3 Recently, lysosomal dysfunction emerged as a potential mechanism of nanomaterial

4 toxicity. ${ }^{[78]}$ Additionally, a lysosome-based process known as autophagy was recognized

5 as an important pathway of cell death. ${ }^{[79]}$ Several studies have revealed that GO could

6 induce autophagy in macrophages. The autophagy was triggered by GO in a

7 concentration-dependent manner, as evidenced by the appearance of autophagic vacuoles

8 and activation of autophagic marker proteins. With a higher concentration of GO, an

9 increase in autophagic vacuoles was observed. It was also shown that autophagy was at

10 least partly regulated by the TLR pathway. ${ }^{[80]}$ GO induced autophagosome accumulation

11 and the conversion of LC3-I into LC3-II, inhibiting the degradation of the autophagic

12 substrate p62 protein. ${ }^{[81]}$ It was also observed that GO exerted a concentration-dependent

13 increase in membrane rafts and the production of phagosomes. GO exposure induced cell

14 necrosis, inflammatory responses, increase in the oxidative stress response and autophagy

15 in RAW 264.7 cells. ROS was also found to induce autophagy by the ROS-Nrf2-p62

16 pathway. ${ }^{[82]}$

17 It is worth noting that the oxidation states of GO may also affect toxicity in macrophages.

18 The reduced GO (rGO) was more toxic than $\mathrm{GO}$ in both bone marrow-derived 19 macrophages and J774A.1 cells. ${ }^{[83]}$ In addition, it was also found that hydrated GO, a 20 material with high density of carbon radicals, was responsible for cell death in THP-1

21 cells as a consequence of lipid peroxidation of the surface membrane and membrane lysis. $22 \quad[84]$

23 Cellular uptake of GO in macrophages 
1 The majority of studies on GO-mediated cellular uptake have been carried out on

2 macrophages. It was evident that the phagocytic capacity of macrophages can be altered

3 after internalizing GO. GO accumulation inside cells causes significant morphological

4 modifications and reduction of macrophage phagocytic ability. ${ }^{[85]}$ In a study aimed to

5 understand the effect of GO when macrophages encounter microbial pathogens, the

6 uptake of GO by macrophages could modulate their capability to phagocytose yeasts. In

7 particular, it was found that the ingestion of heat-killed yeasts was increased by murine

8 peritoneal macrophages after GO treatment. ${ }^{[86]}$ Other studies have shown that, following

9 uptake, GO accumulates primarily in the cytoplasm ${ }^{[85]}$ and the lysosomes. ${ }^{[81]}$ It was

10 found that GO nanosheets were localized on F-actin filaments inducing cell-cycle

11 alterations, apoptosis and oxidative stress in RAW 264.7 cells. ${ }^{[87]}$ In another study, GO

12 sheets were observed within vesicles as well as in the cytoplasm of carp leukocyte cells

13 (CLC), a surrogate cell type for carp macrophages. ${ }^{[88]}$ In RAW 264.7 macrophages the

14 mechanism of GO internalization is dependent on clathrin-coated membrane

15 invagination. ${ }^{[89]}$ Different sizes of GO with BSA functionalization culminated in

16 different pathways. GO of $500 \mathrm{~nm}$ lateral size mainly penetrated the cell through clathrin-

17 mediated endocytosis, while larger sheets ( $1 \mu \mathrm{m}$ lateral size $)$ were internalized by a

18 combination of clathrin-mediated endocytosis and phagocytosis. ${ }^{[90]}$

19 A certain number of studies have shown that the size of GO plays an important role in

20 determining the efficiency of macrophage cellular uptake, with smaller GO nanoparticles

21 being better internalized. ${ }^{[61,91-94]}$ Our group showed that small lateral size GO internalizes

22 better and induced stronger changes in the physiological functions of human and murine

23 primary macrophages. [95] Similar results were observed in murine peritoneal

24 macrophages. In contrast, other researchers reported that the lateral size of GO does not

25 affect cellular uptake. ${ }^{[96,97]}$ It has been demonstrated that the cell uptake of GO of $2 \mu \mathrm{m}$ 
1 and $350 \mathrm{~nm}$ penetrate in the same way and accumulate in similar amounts in murine

2 J774.1A1 macrophages and peritoneal macrophages. This was attributed to similar

3 antibody opsonization and active $\mathrm{Fc} \lambda$ receptor-mediated phagocytosis. ${ }^{[98]}$ Using smaller

4 GO (e.g., $89 \mathrm{~nm}$ and $277 \mathrm{~nm}),{ }^{[99]}$ the uptake into macrophages was again independent of

5 GO size and incubation time.

6 Surface charge also affects the cellular uptake of GO. Luo et. al. ${ }^{[98]}$ synthesized $\sim 200$

$7 \mathrm{~nm}$ of GO functionalized with PEG, bovine serum albumin (BSA), and

8 poly(ethyleneimine) (PEI). The authors found that decoration with PEG and BSA

9 inactivated endocytosis, whereas the positively charged GO-PEI facilitated endocytosis

10 only initially. They hypothesized that after cellular internalization, GO-PEI disrupts the

11 physiological potential and integrity of mitochondria and subsequently alters the levels

12 of ROS and cytochrome C. Similarly, in RAW 264.7 cells, ${ }^{[99]}$ PEI-functionalized GO

13 conjugate with a positive zeta-potential was much easily internalized than GO

14 functionalized with a 6-armed PEG with a negative zeta-potential, although the cellular

15 uptake pathways were the same. This is probably because GO sheets with a positive

16 potential surface were able to better attach to the cell membrane leading to cell

17 internalization. It was indeed observed that the nanomaterials were first transferred to the

18 cell membranes, and then underwent invagination and vesicle formation.

19 The other two parameters that influence the cellular uptake of macrophages are the

20 dispersibility and functionalization of GO. Our group recently demonstrated that reducing

21 GO agglomeration in the presence of proteins and obtaining stable GO dispersions in cell

22 culture media allows faster and more efficient internalization in RAW 264.7

23 macrophages. ${ }^{[100]}$ Several reports showed that the cell penetration of 1-arm PEGylated

24 GO nanosheets was higher than GO modified with a 6-arm PEG. ${ }^{[101,102]}$ The possible 
1 reason is that the latter GO needs a stronger driving force and more energy to cross the

2 cell membrane. The polymer-GO nanosheets functionalized by either amide bond

3 (amPEG-PEI-GO) or disulfide linkage (ssPEG-PEI-GO) could reduce the non-specific

4 uptake and clearance by RAW 264.7 macrophages, increasing their accumulation in

5 targeted cells. ${ }^{[103]} \mathrm{Pi}$ et al. ${ }^{[104]}$ prepared the mannosylated and PEGylated GO

6 nanoplatform (GO-PEG-MAN), which showed significantly increased human THP-1-

7 derived macrophages uptake through an improved mannose receptor-mediated

8 endocytosis in vitro. GO-PEG-MAN loaded with rifampicin was reported to increase

9 cellular uptake of the drug, extending its effect. This suggested that GO-PEG-MAN

10 would be a good candidate for drug delivery. In addition, the oxidation states of GO may

11 also affect macrophage uptake, with GO having greater cell membrane affinity compared

12 to rGO. Although GO was found to induce expression of antioxidative enzymes and

13 inflammatory factors, rGONPs had surprisingly higher cellular uptake and higher $N F-\kappa B$

14 expression. Both GO and rGO were shown to damage F-actin cytoskeleton. ${ }^{[105]}$

\section{Inflammation and macrophage polarization}

16 Macrophages play an important role in pro- and anti-inflammation and can decrease the

17 immune reactions through the production of cytokines. Several studies have evaluated the

18 cytokine release induced by GO in macrophages. GO (with two different sizes of $\sim 2.4$

$19 \mu \mathrm{m}$ and $\sim 200 \mathrm{~nm}$ ) enhanced the production of IL-2, IL-10, IFN- $\gamma$ and TNF- $\alpha$ in a dose-

20 dependent manner. The treatment of RAW 264.7 macrophages with GO stimulated toll-

21 like receptor (TLR) signaling and triggered cytokine responses. ${ }^{[80]}$ Other studies reported

22 that GO can induce cellular necrosis mediated by activation of TLR4 and production of

23 autocrine tumor necrosis factor receptor (TNF-R). ${ }^{[83]}$ In addition, PEG-modified GO 
1 significantly enhanced the secretion of TNF- $\alpha$ by RAW 264.7 macrophages without 2 changing the levels of IL-6 and IL-1 $\beta .{ }^{[102]}$

3 Several factors can affect cytokine expression including GO concentration. IL-6 4 expression in RAW 264.7 cells was increased with 15.6 and $31.25 \mu \mathrm{g} / \mathrm{mL}$ of GO, while 5 no influence was observed at the concentration higher than $62.5 \mu \mathrm{g} / \mathrm{mL}$. Similarly, low 6 concentration of GO increased the synthesis of MIP-1 $\alpha$ and MIP-1 $\beta$, but high 7 concentration of GO decreased their synthesis. ${ }^{[106]}$ Low concentration of GO can 8 stimulate the pro-inflammatory response in RAW 264.7 macrophages. The level of TNF$9 \alpha$ and IL-8 increased rapidly at the GO concentration of $0.01 \mu \mathrm{g} / \mathrm{mL}$ and then decreased 10 at 0.1 and $1.0 \mu \mathrm{g} / \mathrm{mL}$. In addition, the content of malondialdehyde, glutathione and 11 superoxide dismutase increased in a dose-dependent manner following treatment with 12 GO. ${ }^{[107]}$

13 The lateral size of GO is also important in cytokine expression. For example, small and 14 thin GO (lateral dimensions ranged between $50 \mathrm{~nm}$ and $2 \mu \mathrm{m}$ ) dose-dependently inhibited 15 the release of IL-1 $\beta$ and IL- 6 but not TNF- $\alpha$, while NLRP3 inflammasome and caspase161 activation were not affected. This happened because small GO had profound effects on 17 the immunometabolism of the cells, leading to activation of the transcription factor 18 nuclear factor-erythroid 2 related factor 2 , which inhibited the expression of IL-1 $\beta$ and 19 IL-6. ${ }^{[108]}$ The groups of Fadeel and Kostarelos prepared the small (50-300 nm) and large 20 (10-40 $\mu \mathrm{m})$ GO samples of one or two layers' thickness $(1-2 \mathrm{~nm}) .{ }^{[109]}$ The results showed 21 that GO did not trigger size-dependent effects in primary human macrophages, or induce 22 the secretion of Th1 cytokines (e.g., TNF- $\alpha$, IL-6, or IL-1 $\beta$ ) and Th2 cytokines (e.g., IL23 4, IL-5, and IL-13), but significantly suppressed several LPS-induced cytokines, 
1 including the anti-inflammatory cytokine, IL-10. GO elicited also canonical NLRP3-

2 ASC-caspase-1-dependent IL-1 $\beta$ secretion in LPS-primed cells. ${ }^{[109]}$

3 In addition, surface functionalization is another factor that can influence cytokine

4 expression. The immune responses of branched PEI and 6-armed PEG functionalized GO

5 conjugates were studied in RAW 264.7 macrophages. The results indicated that GO-PEG

6 stimulated the macrophage more by improving the secretion of IL-6. ${ }^{[98]}$ On the other

7 hand, another work showed that although PEGylated GO was not internalized by

8 peritoneal macrophages, integrin $\beta 8$-related signaling and cytokine responses were still

9 enhanced. ${ }^{[110]}$ These results point to the conclusion that surface passivation does not

10 always prevent immunological responses to GO nanomaterials.

11 Several studies have evaluated macrophage polarization induced by GO treatment. For 12 example, GO treatment promoted J774A.1 macrophage polarization to the M1 phenotype, 13 with large GO (750-1300 nm) eliciting higher M1 macrophage induction than small GO 14 (50-350 nm) (Fig.4). [94] Fluorescent-PEG-GO nanosheets (FITC-PEG-GO) were 15 effectively absorbed by peritoneal macrophages, increasing yeast phagocytosis by pro16 inflammatory M1 and reparative M2 macrophages. Treatments with GO enhanced M1 17 macrophage activation, which is important for the eradication of pathogens, and 18 diminished alternative activation of M2 macrophages, which decreases fungal persistence 19 and chronic infectious diseases. ${ }^{[111]}$ In addition, a macrophage-targeting/polarizing GO 20 complex (MGC) decreased ROS in immune-stimulated macrophages to attenuate 21 inflammatory polarization of macrophages (M1) Furthermore, it was found that GO 22 functionalized with IL-4 plasmid DNA could polarize M1 to M2 macrophages for the 23 synergistic treatment of myocardial infarction. ${ }^{[112]}$ 
1 In conclusion, the studies conducted in the past several years have clearly evidenced the

2 biological effects of GO on macrophages. GO can reduce cell viability, can be taken up

3 by macrophages and can affect cytokine expression, all these effects being influenced by

4 several factors, such as lateral size, surface charge, dispersibility and functionalization.

5 However, more research is required on macrophage polarization to better understand the

6 possible inflammation risks of GO in macrophages.

\section{Graphene quantum dots}

8 Graphene quantum dots are small graphitic domains with lateral dimensions less than 10

$9 \mathrm{~nm}$ (average $5 \mathrm{~nm}$ ). ${ }^{[47,113]}$ Owing to their high surface area, strong photoluminescent 10 properties, excellent electrical properties, superior chemical inertness and

11 biocompatibility, ${ }^{[114,115]}$ GQDs have potential applications in photovoltaics, ${ }^{[116]}$ anti-

12 microbials, ${ }^{[117-119]}$ bioimaging, ${ }^{[120,121,46]}$ biosensing ${ }^{[122,123]}$ and drug delivery. ${ }^{[124-126]}$

13 With such vast potential uses of GQDs, the study of their cellular effects and toxicity is 14 essential.

15 GQDs were shown to have little effect on cell viability and membrane integrity of 16 activated THP-1-derived macrophages, while significantly increasing ROS, apoptosis, 17 autophagy, and inflammatory responses. ${ }^{[127]}$ Furthermore, GQDs significantly increased 18 the phosphorylation of $\mathrm{p} 38$ MAPK and $\mathrm{p} 65$, and promoted NF- $\kappa \mathrm{B}$. An increased 19 expression of TNF- $\alpha$, IL-1, and IL-8 was observed at low concentrations (10 and 50 $20 \mu \mathrm{g} / \mathrm{mL}$ ), whereas high concentrations (100 and $200 \mu \mathrm{g} / \mathrm{mL}$ ) of GQDs led to opposite 21 effects on cytokine production. It was reported that large (40 nm) GQDs were able to 22 inhibit splenocyte IFN- $\gamma$ production and to modulate MAPKs in J774.1 macrophages. ${ }^{[128]}$

23 Functionalization of GQDs also affected the interactions with macrophages. For instance,

24 thiol functionalized GQDs significantly increased the efflux of oxidized-low density 
1 lipoprotein, down-regulated cell scavenger receptors, and efficiently recovered ROS

2 levels in RAW 264.7 cells. ${ }^{[129,130]}$ GQDs have pure $\mathrm{sp}^{2}$ carbon crystalline structure, while

3 various oxygen functional groups were found in abundance on the surface of graphene

4 oxide quantum dots (GOQDs), which are small fragments of water-soluble GO. ${ }^{[131,132]}$

5 Another study confirmed that folic acid-linked GOQDs were non-toxic to J774.A1

6 macrophages even after prolonged exposure and high concentrations. ${ }^{[133]}$

7 A comprehensive investigation on the uptake pathways, intracellular and nuclear 8 localization and distribution of aminated graphene QDs (AG-QDs) in NR8383 rat

9 alveolar macrophages showed internalization mainly by energy-dependent endocytosis,

10 phagocytosis and caveolae-mediated endocytosis. However, the fluorescence

11 spectrophotometry method used for testing cellular uptake is semi-quantitative, and

12 requires supporting data from alternative methods. The internalized AG-QDs were shown

13 to accumulate in the nucleus (Fig.5), causing nuclear damage and DNA disruption by

14 oxidative stress, direct contact, up-regulation of caspase genes as well as generation of

15 ROS. ${ }^{[133]}$ AG-QDs at $100 \mu \mathrm{g} / \mathrm{mL}$ were also able to trigger genotoxicity. However, the

16 induced DNA damage was not permanent and could be repaired by removing the material

17 and re-incubating the cells in fresh medium. ${ }^{[134]}$

18 Finally, N-doped GQD carriers were developed to enhance the delivery of the promising 19 therapeutic molecule sodium 10-amino-2-methoxyundecanoate into the cells for 20 alleviation of inflammatory diseases. The composite used at the relatively high 21 concentration of $1 \mathrm{mg} / \mathrm{mL}$ up to $24 \mathrm{~h}$ showed anti-inflammatory potential in 22 lipopolysaccharide (LPS)-activated RAW 264.7 macrophages with improved down23 regulation of $C O X-2, i N O S, T N F-\alpha, N F-\kappa B, I L-1 \alpha, I L-1 \beta, I L-4$, and $I L-6$, in comparison 24 to the cells treated with the molecule alone. ${ }^{[135]}$ 
1 In general, GQDs are less toxic in macrophages compared to other GO-based materials.

2 Due to the excellent properties, GQDs can easily enter macrophages through different

3 pathways. The possibility of DNA damage and inflammatory response can be mainly

4 attributed to the uptake of GQDs. However, further systematic investigations involving

5 long-term impact, including the study on exocytosis are necessary.

\section{$6 \quad 2 D$ materials beyond graphene}

7 Based on their unique physical properties, 2D transition metal dichalcogenides (TMDCs)

8 such as $\mathrm{MoS}_{2}, \mathrm{WS}_{2}, \mathrm{MoSe}_{2}$ and $\mathrm{WSe}_{2}$ have been used in various fields ranging from

9 electronic and optoelectronic devices, batteries, sensing and catalysis. ${ }^{[136,137]}$ In this

10 section, beside 2D structures we will also describe the materials in their elemental form

11 as these can be liberated from the different 2D flakes containing them, during processes

12 such as aging and degradation, through processes such as photochemical transformations,

13 oxidation and reduction, dissolution, precipitation, adsorption and desorption,

14 combustion, abrasion and biotransformation. ${ }^{[138]}$ These different forms of elemental

15 material can vary in toxicity. We have chosen a few up-and-coming materials that have

16 been already investigated in electronics and energy storage in lieu of their potential

17 applications in biology. Although few studies have been conducted on macrophages for

18 some of these $2 \mathrm{D}$ materials, we have reviewed the effects on similar compounds

19 containing these elements.

20 Molybdenum disulfide and other forms of molybdenum

21 A trace element existing in various oxidation states, molybdenum is widely used in many

22 industries to make superalloys, nickel-based alloys, lubricants, chemicals, electronics due

23 to its low coefficient of thermal expansion and high thermal conductivity. These

24 properties enable it to enhance material strength, weldability, corrosion resistance and 
1 improve high-temperature creep deformation. ${ }^{[139]}$ Molybdenum can be found naturally

2 in all plants and animals as an enzyme co-factor, and in the environment naturally in the

3 form of molybdenite $\left(\mathrm{MoS}_{2}\right)$, or released from mining activities. [140] Although

4 molybdenum at high doses was found to be toxic in animals, studies in humans have

5 found no long-term danger at doses of up to $1500 \mu \mathrm{g} .{ }^{[141,142]}$

6 Different types of molybdenum compounds have various effects in human and rodent

7 cells. Co-Cr-Mo alloys are commonly used in orthopaedic implants and toxicological

8 studies have been conducted to elucidate the effects of wear and corrosion. Macrophages

9 contact the implant soon after insertion, and have been often used as a cellular model. Co-

10 Cr-Mo alloys have been found to increase IL-6 and M-CSF, and to decrease MCP-1

11 secretion in mouse macrophage J774A.1 cells. ${ }^{[143]}$ In a separate study in MLO-Y4

12 osteocytes, Co-Cr-Mo alloy particles were found to induce $T N F-\alpha$ after $24 \mathrm{~h}$ but

13 downregulated $I L-6$ after 6 h. ${ }^{[144]}$ Most of the toxicity however has been attributed to Co

14 and $\mathrm{Cr}$, due to increased serum and synovial levels of these ions. ${ }^{[145]}$ Conversely, another

15 study in RAW 264.7 macrophages found that Co-Cr-Mo alloys release Co, Cr, Mo ions

16 to host tissues after 3 days, with Co resulting in the highest amount of released ions. The

17 same study also reported that Cr-Co-Mo alloy increased IL-1 $\beta$ secretion. ${ }^{[146]}$

$18 \mathrm{MoCl}_{5}$ was found to induce IL-1 $\beta$ dose-dependently in THP-1 cells and in primary human

19 monocytes, an effect that was found to be caspase 1- and ASC-dependent. ${ }^{[147]}$ The same

20 authors also found that spherical and smooth $1 \mu \mathrm{m}$ Co-Cr-Mo alloy particles did not affect

21 macrophage IL-1 $\beta$, while irregular $1 \mu \mathrm{m}$ Co-Cr-Mo alloy particles increased IL-1 $\beta$. This

22 was carried out in PBMC-derived macrophages and THP-1 cells, and was found to be

23 cathepsin B-dependent. [148] 
1 A more recent study showed that commercial $99.5 \%$ pure molybdenum particles dose-

2 dependently increased IL-1 $\beta$ secretion in primary human macrophages. These particles

3 were also found to increase TNF and IL-6 and activate the NLRP3 inflammasome. ${ }^{[149]}$ A

4 well-characterized 2D molybdenum-based material, $\mathrm{MoS}_{2}$ is the most abundant form of

5 molybdenum and has been thoroughly investigated over the last years. Aggregated $\mathrm{MoS}_{2}$

6 is commonly known to induce strong pro-inflammatory and pro-fibrogenic responses

7 (increasing IL-8, TNF and IL-1 $\beta$ in THP-1 cells), so exfoliation is currently used to

8 decrease its toxicity, ${ }^{[150]}$ although the caveat is that toxicity of $\mathrm{MoS}_{2}$ can also increase

9 with increasing degree of exfoliation. ${ }^{[151]}$

10 The effects of $\mathrm{MoS}_{2}$ can be determined to be mainly through cellular uptake as seen from

11 RAW 264.7 cells and mice ${ }^{[152]}$ as shown in Figure 6. $\mathrm{MoS}_{2}$ accumulates mostly in the

12 liver and spleen but shows no toxicity in RAW 264.7 cells. $\mathrm{MoS}_{2}$ can be oxidized into

13 water-soluble molybdate species (Mo VI), which could explain its total excretion from

14 the body within a month. ${ }^{[153]} \mathrm{MoS}_{2}$ nanoflowers were shown to modulate anti-

15 inflammation in RAW 264.7 macrophages and human bone marrow stem cells, especially

16 when PEGylated and loaded with the TNF- $\alpha$ inhibitor etanercept (ET). ET-loaded

$17 \mathrm{MoS}_{2} @ \mathrm{PEG}$ were non-toxic and inhibited pro-inflammatory markers TNF- $\alpha, C D 86$ and

18 iNOS, while promoting anti-inflammatory markers Arg1, CD206 and $I L-10$. In fact, the

19 addition of PEG to $\mathrm{MoS}_{2}$ was found to evoke stronger cytokine response (e.g., IL-6, TNF-

$20 \alpha, I F N-\gamma, M C P-1)$ than $\mathrm{MoS}_{2}$ alone due to a stronger membrane adsorption and a slower

21 and prolonged membrane penetration. ${ }^{[154]}$

22 Lastly, a study in differentiated THP-1 cells found that $\mathrm{MoS}_{2}$ was internalized within $4 \mathrm{~h}$

23 and partially degraded by $72 \mathrm{~h}$, leading to an increase in intracellular lipid bodies as a

24 mechanism of defence in response to $\mathrm{MoS}_{2} \cdot \mathrm{MoS}_{2}$ interaction with proteins could be 
1 detected, implying a potentially relevant direct impact to other signalling pathways. ${ }^{[155]}$

2 Proven extensively to be non-toxic when not overly-exfoliated, $\mathrm{MoS}_{2}$ evokes

3 inflammatory response although this can be circumvented by adjusting its adjuvants in

4 complex compounds. (Table 1)

5 Our group has very recently found $\mathrm{MoS}_{2}$ to be minimally toxic in human macrophages

6 with slight alterations in cell stress and inflammatory responses. ${ }^{[55]}$ A few years ago we

7 also found that cytotoxicity of $\mathrm{MoS}_{2}$ only emerged after $24 \mathrm{~h}$ upon incubation with the

8 products of $\mathrm{MoS}_{2}$ degradation recovered after $14 \mathrm{~d}$ at concentrations of $50 \mu \mathrm{g} / \mathrm{mL}$. ${ }^{[156]}$

\section{Manganese dioxide and other forms of manganese}

10 Manganese is the fifth most abundant metal, with manganese dioxide the most common 11 naturally-occurring form. Manganese is used in the manufacturing of fireworks, dry-cell

12 batteries, fertilizer, paints, gasoline additives, medical imaging and cosmetics. ${ }^{[157]}$

13 Manganese is important in enzymes involved in cholesterol, amino acid and carbohydrate

14 metabolism. ${ }^{[158]}$ Manganese is very important physiologically as it is crucial in

15 connective tissue, bones, blood-clotting factors, and sex hormones. Manganese also plays

16 a role in fat and carbohydrate metabolism, calcium absorption, regulation of cellular

17 energy, and blood sugar regulation, and is required for normal brain function. ${ }^{[159]}$

18 Manganese was shown to induce iNOS expression in RAW 264.7 macrophages via 19 activation of both MAPK and PI3K/Akt. ${ }^{[160]} \mathrm{Mn}^{2+}$ ions can enter cells through the natural 20 resistance-associated macrophage protein (Nramp) transporters, ${ }^{[161]}$ which are expressed 21 at the phagosomal membrane of macrophages and neutrophils, and also mediate $\mathrm{Fe}^{2+}$ and $22 \mathrm{Co}^{2+}$ uptake. ${ }^{[162]}$ Manganese particles of $40 \mathrm{~nm}$ and agglomerates ranging from $200 \mathrm{~nm}$

23 to over 16 microns were reported to be internalized by rat alveolar macrophages and other 24 cells including BRL 3A rat liver cells and PC-12 rat neuron-like cells. ${ }^{[163]}$ In rat bone 
1 marrow-derived macrophages, PEGylated $\mathrm{MnO}_{2}$ nanoparticles of $15 \mathrm{~nm}$ were non-toxic

2 and did not trigger inflammatory cascades and down-regulated TNF- $\alpha$ secretion when

3 used at $5-100 \mu \mathrm{g} / \mathrm{mL} .{ }^{[164]}$

$4 \mathrm{MnO}_{2}$ nanoparticles were reported to almost completely enter guinea pig alveolar 5 macrophages within an hour, compared to other particles such as $\mathrm{TiO}_{2}$. The uptake also

6 induced chemotaxin production. ${ }^{[165]}$ Lastly, hyaluronic acid-coated, mannan-conjugated

$7 \mathrm{MnO}_{2}$ particles (Man-HA- $\mathrm{MnO}_{2}$ ) were found to prime anti-inflammatory, pro-tumour

8 M2 RAW 264.7 macrophages to a pro-inflammatory M1 form. This enhances the ability

9 of $\mathrm{MnO}_{2}$ to modulate chemoresistance due to down-regulation of hypoxia-inducible

10 factor-1 $\alpha$ (HIF-1 $\alpha)$ and vascular endothelial growth factor (VEGF). (Fig.7). ${ }^{[166]}$ In short,

11 manganese as an element easily enters cells, inducing cell stress responses. (Table 2) With

12 the bulk of toxicity research conducted on the brain and lung, much remains unknown

13 about the effects of manganese on macrophages in other organs, or in other immune cells

14 in general. Likewise, $2 \mathrm{D} \mathrm{MnO}_{2}$ has been barely studied in vitro but its biological effects

15 on cells has been shown to be mainly strong absorption with ssDNA and intrinsic oxidase

16 activity ${ }^{[167]}$ and even antimicrobial activity. ${ }^{[168]}$ We would like to see more studies in

17 future on immune cells, as this will help us better understand the impact of $2 \mathrm{D}^{\mathrm{MnO}_{2}}$ in

18 particular.

19 Hexagonal boron nitride and other forms of boron

20 Boron-containing compounds are predicted to have potent biological activity as boron 21 atoms could interact with a target protein through strong hydrogen bonds and also through

22 covalent bonds. [169] Boron-containing compounds have current applications in

23 biomedicine as anti-fungals, ${ }^{[170]}$ dipeptidyl peptidase-IV inhibitors, ${ }^{[171]}$ antibiotics, ${ }^{[172]}$

24 antivirals ${ }^{[173]}$ and in radiopharmaceuticals ${ }^{[174]}$ Industrially, boron is used to harden steel 
1 and is used for refining nonferrous metals. It is also an additive to enhance semiconductor

2 control and has been used in making glass, food preservatives, cleaning products,

3 antiseptics and agrochemicals. ${ }^{[175]}$

4 Hexagonal boron nitride $(\mathrm{hBN})$ is a form where boron and nitrogen atoms are covalently

5 bound in a hexagonal structure and their layers are stacked and interact through van der

6 Waals forces. ${ }^{[176]}$ Contrary to graphene, whose strength significantly decreases with

7 increasing layers, the mechanical strength of boron nitride is unaffected by increasing

8 thickness. ${ }^{[177]}$ As such, it has been used in the pharmaceutical industry as a tablet

9 lubricant ${ }^{[178]}$ and in the electronics industry as a wide bandgap semiconductor with high

10 thermal and chemical stability. ${ }^{[179]}$

11 Given their association with bone mineral but not connective tissues, ${ }^{[180]}$ boron nitride

12 nanotubes and nanoplatelets have been used as polymeric matrix reinforcement in bone

13 tissue engineering. ${ }^{[181]}$ In oncology, controlled release boron nitride nanospheres were

14 used in prostate cancer treatment through adjusting treatment temperature and nanosphere

15 crystallinity. ${ }^{[182]}$

16 Few studies involving boron compounds have been conducted on macrophages in

17 comparison to more deeply studied materials such as graphene and molybdenum

18 disulfide. In $\mathrm{C} 3 \mathrm{H} / \mathrm{HeJ}$ mouse peritoneal macrophages, boron enhanced $\mathrm{Fc}$-receptor

19 expression and IL-6 production. ${ }^{[183,184]}$ Boron derivatives such as acyclic amine-

20 carboxyboranes were found to inhibit 5'lipoxygenase activity in J774A mouse

21 macrophages and RMPI 1788 human leukocytes, at levels similar to conventional anti-

22 inflammatory drugs such as indomethacin. These boron compounds were also effective

23 enzyme inhibitors of lysosomal acid phosphatase, cathepsins and aryl sulfatase. ${ }^{[185]}$ 
1 In THP-1-derived human macrophages, boron nitride nanotubes (BNNTs) were

2 demonstrated to cause lysosomal destabilization, pyroptosis and inflammasome

3 activation, as seen by an increase in cathepsin B, caspase 1 , IL-1 $\beta$ and IL-18, via the

4 NLRP3 pathway. The macrophage phagocytic capacity was also suppressed (Fig.8). ${ }^{[186]}$

5 In peritoneal macrophages from BALB/c mice, boron induces lymphocyte proliferation

6 and further stimulated secretion of TNF- $\alpha$, IL-6, IL-1 $\beta$, NO and expression of iNOS. ${ }^{[187]}$

7 Pectin-coated boron nitride nanotubes were reported to be non-toxic in RAW 264.7

8 macrophages at concentrations up to $50 \mu \mathrm{g} / \mathrm{mL}$ for $24 \mathrm{~h}$ and were internalized without

9 impairing cell structures or triggering release of inflammatory cytokines (IL-6, IL-10,

10 TNF- $\alpha$ ), apoptosis and oxidative stress. These nanoparticles were confined within the

11 endoplasmic compartment and failed to localize with lysosomes. Interestingly, these

12 nanotubes were shown to down-regulate the pro-inflammatory cytokine $I L-1 \beta$, although

13 more studies from different labs need to be conducted to confirm this contrasting finding.

$14[188]$

15 In short, boron has shown to be non-toxic in general, possibly due to its suppression of 16 macrophage phagocytosis, although it has been shown to induce inflammatory responses

17 which could be indirectly linked to its inhibitory effects on cellular uptake. (Table 3) As

18 most of the studies conducted are on non-BN materials, it would be interesting to

19 investigate the effect of $2 \mathrm{D} \mathrm{hBN}$, which is rapidly increasing in use in materials science 20 and biomedicine, on macrophages.

\section{Other 2D materials}

22 There are other promising 2D materials such as black phosphorus and tungsten, which

23 have not been as popular as the earlier-mentioned examples of molybdenum, manganese

24 and boron, but have come into view as scientists explore their unique properties. These 
1 materials may not be as well-studied and more research is needed to better manipulate

2 and produce materials with favorable stability and toxicity profiles. These can then be

3 subsequently used for various biomedical purposes.

4

5 Thin layer black phosphorus (BP) is a versatile semi-conductor, having a tunable direct

6 bandgap and high carrier mobilities. ${ }^{[189]}$ Most 2D materials are good photodetectors in

7 the visible range and black phosphorus is one of the few that can extend the spectral range

8 to mid-infrared. ${ }^{[190]}$ Black phosphorus is unfortunately easily degraded under

9 environmental conditions, reacting with oxygen in water even in the absence of light,

10 decomposing into $\mathrm{PO}_{2}, \mathrm{PO}^{3-}$, and $\mathrm{PO}_{4}{ }^{3-} \cdot{ }^{[191]}$ This is advantageous, given that phosphorus

11 is already a main component in DNA and RNA, the building blocks of life. ${ }^{[192]}$

12 Hinging on their use as field-effect transistors, black phosphorus quantum dots have been

13 used as chemiluminescence emitters to detect copper, ${ }^{[193]}$ or in the form of nanosheets to

14 detect $\mathrm{H}_{2} \mathrm{O}_{2},{ }^{[194]}$ microRNA, ${ }^{[195]}$ or as a metal-free co-catalyst for photocatalytic nitrogen

15 fixation. ${ }^{[196]}$ Relevant to biomedicine, black phosphorus quantum dots have been found to reduce the thermal stability of human serum albumin by decreasing the $\alpha$-helix

17 structure but increasing the $\beta$-sheets. ${ }^{[197]}$ Black phosphorus nanosheets were shown to

18 bind to BSA and bovine haemoglobin (BHB), leading to the partial destruction of certain

19 segments on BHB through alteration of tertiary structure. ${ }^{[198]}$

20 Although no data in macrophages is currently available, layered black phosphorus was

21 found to be toxic only above $50 \mu \mathrm{g} / \mathrm{mL}$ in A549 human lung cancer cells. This toxicity 22 was lower than graphene oxides but higher than exfoliated transition-metal

23 dichalcogenides such as $\mathrm{MoS}_{2}, \mathrm{WS}_{2}, \mathrm{WSe}_{2} \cdot{ }^{[199]}$ Notably, the mechanisms of toxicity of 24 black phosphorus was linked to ROS production and disruption of cell membrane 
1 integrity. Interestingly, large layered black phosphorus $(\sim 884 \mathrm{~nm} \pm 102.2 \mathrm{~nm})$ was

2 identified to have higher cytotoxicity than small ones $(\sim 208.5 \mathrm{~nm} \pm 46.9 \mathrm{~nm})$. ${ }^{\text {[200] }}$

3 Black phosphorus quantum dots with titanium sulphonate ligands (derived from addition

4 of p-toluenesulfonic acid to $\mathrm{Ti}(\mathrm{OiPr})_{4}$ and subsequently heated to remove $\left.\mathrm{EtOH}\right)$ to

5 improve biocompatibility resulted in upregulation of the macrophage and lymphocyte

6 inflammation marker CD68+ cells in mouse lungs, with no toxicity reported in RAW

7264.7 macrophages. These quantum dots escaped macrophage uptake and induced low

8 ROS production. Black phosphorus quantum dots without the titanium ligand showed a

9 decrease in ATP production in J774A.1 macrophages and lysosomal swelling, and

10 increased neutrophil generation in treated mice, implying inflammatory response. ${ }^{[201]}$

11 Lastly, black phosphorus quantum dots and nanosheets induce immunotoxicity and

12 immune perturbation in differentiated THP-1-derived macrophages in the presence of a

13 plasma corona. It is well-known that the protein corona affects nanomaterial/cell

14 interactions. In this case, it was found that the corona influenced cellular uptake, activated

$15 \mathrm{NF}-\kappa \mathrm{B}$ and increased NOS and TNF secretion. In THP-1-derived macrophages, there was

16 increased IL-1 $\beta$, IL-6, IL-8 and IFN- $\lambda$, while in human peripheral blood macrophages,

17 there was increased level of IL-1 $\beta$, IL-6, IL-8, IL-9 and IL-10. Both materials were also

18 found to be slightly toxic in H1299 human lung cancer cells, L0-2 human hepatic cells,

19 293T human embryonic kidney cells, THP-1 macrophages and human peripheral blood

20 macrophages. (Fig.9) ${ }^{[202]}$

21 The same authors reported also that black phosphorus nanosheet-corona complexes of

$22207 \mathrm{~nm}$ promoted M1 polarization of RAW 264.7 macrophages and interacted with

23 calmodulin to facilitate $\mathrm{Ca}^{2+}$ influx in this type of cells, which thereafter induced

24 activation of the $\mathrm{p} 38-\mathrm{MAPK}$ and $\mathrm{p} 65-\mathrm{NF}-\mathrm{\kappa B}$ pathways, with no apparent involvement of 
1 JNK and ERK pathways. Black phosphorus-corona complex-exposed macrophages

2 upregulated expression of M1-related markers TNF- $\alpha, i N O S, I L-12 p 40$ and CD16.

3 Interestingly, the presence of the corona on the black phosphorus was sufficient to

4 promote phagocytosis of cancer cells by macrophages, in a co-culture. mRNA levels of

5 M2-related genes $I L-10, C D 206$ and arginase-I were decreased in agreement with M1

6 polarization. ${ }^{[203]}$ In general, black phosphorus can induce inflammatory effects and leads

7 to pro-M1 macrophage phenotypes, with toxicity remaining cell-type-dependent. (Table

$84)$

9 Tungsten nanomaterials

10 Naturally found in rocks and soils, tungsten is made into strong and flexible alloys that

11 conduct electricity well. Tungsten is a component of light bulb filaments, ceramic

12 pigments, fabric fire-retardant coatings and fade-resistant dyes, turbine blades, welding

13 electrodes, fishing weights, golf clubs and bullets. ${ }^{[204]}$ Many tungsten compounds have

14 been explored in various applications. Tungsten oxide (WO) mesoporous silica

15 nanoparticles were linked to the pro-apoptotic gene Bax for cancer photothermal therapy

16 (PTT). ${ }^{[205]}$ WO nanoparticles were incorporated into cloth as a flexible pH sensor. ${ }^{[206]}$

17 Tetrathiotungstate has been investigated as an anti-copper drug, ${ }^{[207]}$ and $\mathrm{WSe}_{2}$ nanosheets

18 were used as a glucose sensor. ${ }^{[208]}$

19 The effects of tungsten are multi-faceted and have been mostly investigated in terms of

20 genetic changes, oxidative stress and cytokine production. $\mathrm{WO}_{3}$ nanoparticles were found

21 to increase rat liver enzymes and to cause DNA damage in peripheral blood leukocytes

22 and liver. ${ }^{[209]}$ The same authors reported cell cycle inhibition and induced apoptotic death

23 with $\mathrm{WO}_{3}$ nanoparticles in A549 human lung cancer cells, with toxicity seen only at high 
1 concentrations above $200 \mu \mathrm{g} / \mathrm{mL} .^{[210]}$ Toxicity in macrophages can therefore be

2 extrapolated by considering the trend in other cell types such as A549 cells.

3 The immune effects of tungsten are complex. Oral tungstate (NaW) up to $125 \mathrm{mg} / \mathrm{kg}$ per

4 day for up to 70 days showed preferential uptake in rat immune organs, including the

5 femur, spleen and thymus. ${ }^{[211]}$ In rats, tungstate was reported to decrease general

6 cytotoxic $\mathrm{T}$ cell activity in one study ${ }^{[212]}$ but activate spleen cytotoxic and helper T cells,

7 with immunosuppressive effects linked to co-exposure to immune stress. The percentage

8 of monocytes was also found to be lower at higher tungstate concentrations. ${ }^{[213]}$

9 In PBMCs, tungsten carbide-cobalt (WC-Co) particles of $<1 \mu \mathrm{m}, 99.5 \%$ purity, $100 \mu \mathrm{g}$

$10 / \mathrm{mL}$, were shown to activate p38 and stabilize HIF-1a and p53, while expressing the

11 oxidase stress response gene HMOX1. ${ }^{[214]}$ In JB6 cell and rat lung macrophages, WC-Co

12 nanoparticles were seen to induce apoptosis and ROS production. ${ }^{[215]}$

13 Although few studies exclusively on macrophages have been conducted, tungsten carbide

14 has been found to be effective bio-cargo for macrophages in photothermal therapy. ${ }^{[216]}$

15 A THP-1 cell and Beas-2B lung epithelium co-culture with WC-Co nanoparticles with a

16 WC grain size of $80 \mathrm{~nm}$ reported increased IL-1 $\beta$, IL-12 and decreased TNF- $\alpha$. Toxicity

17 was already observed from $10 \mu \mathrm{g} / \mathrm{mL}$, with increased expression of CD40. ${ }^{[217]}$ The anti-

18 inflammatory polyoxotungstate- $1\left(3 \mathrm{Na}_{2} \mathrm{WO}_{4} \cdot 9 \mathrm{WO}_{3} \cdot \mathrm{H}_{2} \mathrm{O}\right)$ at up to $100 \mu \mathrm{M}$ was found to

19 prevent TNF- $\alpha$ and nitric oxide release from LPS-treated murine macrophages, and to

20 decrease ATP-induced IL-1 $\beta$ release. ${ }^{[218]}$ In RAW 264.7 macrophages, it was reported

21 that tungstate nanoparticles led to ROS production without leading to DNA damage nor

22 production of IL-6, IL-8 or TNF- $\alpha$. Cells engulfing these nanoparticles are as shown in

23 Figure 10. ${ }^{[219]}$ 
1 Tungstate $\left(\mathrm{Na}_{2} \mathrm{WO}_{4}\right)$ reduced LPS-induced IL-10, TNF- $\alpha$ and IL-6 in THP-1 cells and

2 altered cell cycle progression. ${ }^{[220]}$ An intra-tracheal rat study showed neither acute local

3 pulmonary inflammation nor IL-6 production with WC-Co nanoparticles. There was also

4 no increase in alveolar macrophage or activation despite nanoparticle phagocytosis. ${ }^{\text {[221] }}$

5 In short, despite contradicting reports about its toxicity, tungsten compounds have proven

6 to be inflammatory in some cell types without increasing TNF- $\alpha$, but it is clear that they

7 induce oxidative stress, which could culminate in compensatory intracellular stress

8 response mechanisms. (Table 5) There have been sparse in vitro data on the effects of 2D

9 tungsten compounds in immune cells although it has been found that human skin

10 fibroblasts preferentially adhere to tungsten compared to silicon oxide in a $2 \mathrm{D}$ tungsten-

11 silicon oxide composite ${ }^{[222]}$ and that no histological abnormalities were reported in mouse

12 heart, liver, spleen, lungs or kidney after 16 days of 2D tungsten nitride nanosheets. ${ }^{\text {[223] }}$

13 Another paper also reported no histological organ abnormalities after 30 days although

14 high levels of $2 \mathrm{D} \mathrm{WS}_{2}$-PEG nanosheets were found in the liver and spleen. ${ }^{[153]} \mathrm{We}$

15 included this element in our review as it is an emerging 2D nanomaterial. In fact, we hope

16 there will be more studies in future on immune cells, as this will help us better understand

17 the biological impact of 2D tungsten compounds.

\section{Summary and future outlook}

19 Macrophages are efficient phagocytes and their main interaction with $2 \mathrm{D}$ materials is

20 related to uptake, which includes mechanisms such as phagocytosis, endocytosis and

21 direct trans-membrane transport. Once in the cell, these materials end up in various

22 intracellular locations such as endosomes, lysosomes or the cytosol. ${ }^{[224,225]}$ This

23 heterogenous uptake makes it contentious to pinpoint material interaction with specific 
1 mechanisms. Our review has therefore focused on the effects of macrophages after they

2 encounter various 2D materials.

3 Our review has summarized macrophage studies on various 2D materials and found the

4 bulk of the effects to be related to inflammation. Graphene family materials have in

5 general been found to affect inflammatory cytokines in macrophages. Individually, FLG

6 was found to induce apoptosis, damage cell membrane and decrease viability, while GO

7 can polarize macrophages to a pro-inflammatory form. In contrast, GQDs had little effect

8 on viability and membrane integrity but increased ROS, inflammation and apoptosis.

9 TMDCs exhibited less toxicity and inflammation than graphene materials in general, with

$10 \mathrm{MoS}_{2}$ increasing intracellular lipids and potentially interacting with proteins, and with

$11 \mathrm{MnO}_{2}$ increasing cell stress and polarizing macrophages to a pro-inflammatory form.

12 Other 2D materials such as boron nitride could increase inflammation despite lower

13 toxicity due to decreased macrophage phagocytosis while black phosphorus was less

14 toxic than GO, but more than TMDCs due to ROS- and membrane disruption-linked

15 mechanisms. Black phosphorus also promoted macrophage polarization to pro-

16 inflammatory subtypes. Lastly, tungsten, despite having sparse data on 2D forms, had

17 contrasting effects on macrophage toxicity in different studies and increased

18 inflammation and ROS without displaying genotoxicity (Fig.11).

19 Low-dimensional nanomaterials (OD to 2D) could mechanically affect plasma and

20 lysosomal membranes, leading to frustrated phagocytosis and cytotoxicity. In general,

21 mechanical stress or damage occurs when cells try to pack rigid structures into spherical

22 lysosomes. ${ }^{[21]}$ Using graphene family members as an example, these materials can be

23 classified as 0D fullerenes and carbon nanodots, 1D carbon nanotubes, 2D graphene,

24 graphene oxides and graphene nanoribbons, and 3D nanodiamonds. ${ }^{[226]}$ With fullerene 
1 as an exception for size (the smallest 0D material), toxicity may increase with material

2 dimension in macrophages, given that 3D nanodiamonds were found to cause no immune

3 response ${ }^{[227]}$ while $0 \mathrm{D}, 1 \mathrm{D}$ and $2 \mathrm{D}$ materials were found to be taken up by macrophages

4 and can cause cytotoxicity. ${ }^{[55,228]}$ It is however important to note that the mechanisms of

5 material toxicity are very complex, with additional factors such as lateral size and rigidity

6 coming into play. This makes it difficult to identify a particular mechanism or interaction

7 type that could be responsible for material toxicity.

8 Nanomaterial rigidity can also affect toxicity, with rigid non functionalized CNTs found

9 to induce more inflammation than flexible functionalized CNTs. ${ }^{[229,230]}$ In the case of 2D

10 materials, the intrinsic structure of the material and resultant physicochemical properties,

11 such as material flexibility and ease of stacking, allow toxicity prediction. Rigidity also

12 increases in general with thickness, which impedes completion of material phagocytosis.

$13{ }^{[231]}$ A phenomenon of incomplete uptake of large foreign material relative to cell size,

14 frustrated phagocytosis has been extensively reported with 1D materials such as CNTs in

15 macrophages, with longer CNTs causing greater effects. ${ }^{[232]}$ However, 2D graphene

16 nanoplatelets have also been found to cause frustrated phagocytosis in macrophages due

17 to their aerodynamic properties and consequent rigidity. ${ }^{[231,233]}$ Unsurprisingly, frustrated

18 phagocytosis is also affected by material lateral size. It has been reported that

19 macrophages are at higher risk of frustrated phagocytosis in the presence of graphene

20 materials with a lateral size of more than $20 \mu \mathrm{m} .{ }^{[233,234]}$ However, with the bulk of

21 macrophage 2D material research carried out with sub-micrometer materials, frustrated

22 phagocytosis may not be as prominent as that observed with 1D materials.

23 Different 2D materials have potentially different effects in the cells of different

24 individuals and the various methods of synthesizing 2D materials and measuring 
1 inflammation may make it difficult to compare results from different labs. Additionally,

2 2D materials may impact cells differently in the presence of different cell culture media,

3 and have different dispersion stability due to the peripheral protein corona effect. ${ }^{[235]}$ In

4 some cases such as manganese and tungsten which are not as well-studied as graphene,

5 we have covered the biological effects of non-2D forms of the same elemental material

6 in macrophages in an attempt to provide a starting point for understanding and predicting

7 its effect in 2D form.

8 Most work on 2D materials have been conducted short-term, and on specific subsets of 9 macrophages or cell lines, and may not be fully transferable to in vivo human research

10 which consists of much greater complexity. In a number of newer $2 \mathrm{D}$ materials, this

11 research has been conducted mainly in target organs such as the brain and lung, where

12 side effects have been predicted to occur. It is also pertinent to investigate the long-term

13 effects of 2D materials, and to include consequent data on material biodegradation if 14 possible.

15 At this point, it is unknown if material uptake is required for toxicity effects and if toxicity 16 is an indirect effect of macrophage activation. Much also depends on various factors such 17 as material, time-point and dose, which may differ from study to study. It is important to 18 note that many factors impact uptake and therefore toxicity, such as surface charge, ${ }^{[98]}$ 19 dispersibility ${ }^{[100]}$ and functionalization. ${ }^{[103]}$ However, it is difficult to correlate 20 nanomaterial properties to toxicity and to complicate matters, some of these properties 21 such as charge, inertness and colloidal stability may be linked. ${ }^{[10]}$ Seeing the huge range 22 in lateral size of $2 \mathrm{D}$ materials used in these macrophage studies, it may be challenging to 23 generalize trends. Despite this, it may be possible to predict increasing nanoparticle 24 toxicity with smaller materials $(<100 \mathrm{~nm})$ potentially due to increased uptake. ${ }^{\text {[236] }}$ 
1 Knowing which and how 2D materials affect the body is crucial to better design new

2 materials with minimal toxicity. The roadmap ahead may include many more innovative

3 2D materials that have yet emerged from anonymity, which would require extensive

4 safety testing in immune cells before widespread commercial use. We could even see the

5 advent of up-and-coming 2D materials such as arsenene, antimonene, germanene,

6 stanene, and silicene, which have already made inroads into electronic applications. ${ }^{[22]}$

7 This would make the current work in macrophages a solid foundation on which to better

8 investigate future 2D materials.

\section{Acknowledgments}

10 The authors gratefully acknowledge the financial support from the EU Graphene Flagship

11 project (no. 881603). This work was partly supported the Agence Nationale de la

12 Recherche (ANR) through the LabEx project Chemistry of Complex Systems (ANR-10-

13 LABX-0026_CSC). We wish to acknowledge the Centre National de la Recherche

14 Scientifique (CNRS) and the International Center for Frontier Research in Chemistry

15 (icFRC).

16 Disclosure statement

17 No potential competing interest was reported by the authors.

18 ORCID

19 Alberto Bianco https://orcid.org/0000-0002-1090-296X

\section{References}

22 [1] Chaplin, D.D. Overview of the Immune Response. Allergy Clin Immunol. 2010. 125(2 Suppl 2), S3-23. 
[2] Safari, H.; Kelley, W.J.; Saito, E.; Kaczorowski, N.; Carethers, L.; Shea, L.D.;

Eniola-Adefeso, O. Neutrophils preferentially phagocytose elongated particles-An opportunity for selective targeting in acute inflammatory diseases. Sci Adv. 2020. 6(24), eaba1474.

[3] Gustafson, H.H.; Holt-Casper, D.; Grainger, D.W.; Ghandehari, H. Nanoparticle Uptake: The Phagocyte Problem. Nano Today. 2015. 10(4), 487-510.

[4] Weissleder, R.; Nahrendorf, M.; Pittet, M.J. Imaging macrophages with nanoparticles. Nat. Mater. 2014. 13(2), 125-38.

[5] Murray, P.J.; Wynn, T.A. Protective and pathogenic functions of macrophage subsets. Nat. Rev. Immunol. 2011. 11(11), 723-737.

[6] Gordon, S.; Martinez, F.O. Alternative activation of macrophages: mechanism and functions. Immunity. 2010. 32(5), 593-604.

[7] Nakayama, M. Macrophage recognition of crystals and nanoparticles. Front Immunol. 2018. 9,103.

[8] Borgognoni, C.F.; Kim, J.H.; Zucolotto, V.; Fuchs, Riehemann, H.K. Human macrophage responses to metal-oxide nanoparticles: a review. Artif. Cells Nanomed. Biotechnol. 2018. 46(Suppl 2), 694-703.

[9] Saha, K.; Rahimi, M.; Yazdani, M.; Kim, S.T.; Moyano, D.F.; Hou, S.; Das, R.; Mout, R.; Rezaee, F.; Mahmoudi, M.; Rotello, V.M. Regulation of macrophage recognition through the interplay of nanoparticle surface functionality and protein corona. ACS Nano. 2016. 10(4), 4421-4430.

[10] Rivera-Gil, P.; de Aberasturi, D.J.; Wulf,V.; Pelaz, B.; del Pino, P.; Zhao, Y.; de la Fuente, J.M.; de Larramendi, I.R.; Rojo, T.; Liang, X.J.; Parak, W.J. The challenge to relate the physicochemical properties of colloidal nanoparticles to their cytotoxicity. Acc. Chem. Res. 2013. 46(3), 743-749.

[11] Huang, Y.; Hung, K.C.; Hung, H.S.; Hsu, S.H. Modulation of macrophage phenotype by biodegradable polyurethane nanoparticles: possible relation between macrophage polarization and immune response of nanoparticles. ACS Appl. Mater. Interfaces. 2018. 10(23), 19436-19448.

[12] Herd, H.; Bartlett, K.T.; Gustafson, J.A.; McGill, L.D.; Ghandehari, H. Macrophage silica nanoparticle response is phenotypically dependent. Biomaterials. 2015. 53, 574-582.

[13] Hoppstadter, J.; Dembek, A.; Linnenberger, R.; Dahlem, C.; Barghash, A.; Fecher-Trost, C.; Fuhrmann, G.; Koch, M.; Kraegeloh, A.; Huwer, H.; Kiemer, A.K. 
Toll-Like receptor 2 release by macrophages: an anti-inflammatory program induced by glucocorticoids and lipopolysaccharide. Front Immunol. 2019. 10, 1634. [14] Brzicova, T.; Javorkova, E.; Vrbova, K.; Zajicova, A.; Holan, V.; Pinkas, D.; Philimonenko, V.; Sikorova, J.; Klema, J.; Topinka, J.; Rossner Jr, P. Molecular responses in THP-1 macrophage-like Cells exposed to diverse nanoparticles. Nanomaterials. 2019. 9(5), 687.

[15] Yu, K.; Chang, S.H.; Park, S.J.; Lim, J.; Lee, J.; Yoon, T.J.; Kim, J.S.; Cho, M.H. Titanium dioxide nanoparticles induce endoplasmic reticulum stress-mediated autophagic cell death via mitochondria- associated endoplasmic reticulum membrane disruption in normal lung cells. PLoS One. 2015. 10(6), 0131208. [16] Yu, K.; Yoon, T.J.; Minai-Tehrani, A.; Kim, J.E.; Park, S.J.; Jeong, M.S.; Ha, S.W.; Lee, J.K.; Kim, J.S.; Cho, M.H. Zinc oxide nanoparticle induced autophagic cell death and mitochondrial damage via reactive oxygen species generation. Toxicol. In Vitro. 2013. 27(4), 1187-1195.

[17] Guo, C.; Wang, J.; Jing, L.; Ma, R.; Liu, X.; Gao, L.; Cao, L.; Duan, J.; Zhou, X.; Li, Y.; Sun, Z. Mitochondrial dysfunction, perturbations of mitochondrial dynamics and biogenesis involved in endothelial injury induced by silica nanoparticles. Environ. Pollut. 2018. 236, 926-936.

[18] Sipos, A.; Kim, K.J.; Sioutas, C.; Crandall, E.D. Evidence for nanoparticleinduced lysosomal dysfunction in lung adenocarcinoma (A549) cells. Int. J. Mol. Sci. 2019. $20(21), 5253$.

[19] Khatri, M.; Bello, D.; Pal, A.K.; Cohen, J.M.; Woskie, S.; Gassert, T.; Lan, J.; Gu, A.Z.; Demokritou, P.; Gaines, P. Evaluation of cytotoxic, genotoxic and inflammatory responses of nanoparticles from photocopiers in three human cell lines. Part. Fibre Toxicol. 2013. 10, 42.

[20] Schins, R.P.F. Mechanisms of genotoxicity of particles and fibers. Inhal. Toxicol. 2002. 14(1), 57-78.

[21] Wang, Z.; Zhu, W; Qiu, Y.; Yi, X.; von dem Bussche, A.; Kane, A.; Gao, H.; Koski, K.; Hurt, R. Biological and environmental interactions of emerging twodimensional nanomaterials. Chem. Soc. Rev. 2016. 45(6), 1750-1780.

[22] Fadeel, B.; Bussy, C.; Merino, S.; Vázquez, E.; Flahaut, E.; Mouchet, F.; Evariste, L.; Gauthier, L.; Koivisto, A.J.; Vogel, U. et al. Safety Assessment of Graphene-Based Materials: Focus on Human Health and the Environment. ACS Nano. 2018. 12(11), 10582-10620. 
[23] Le, T.; Oh, Y.; Kim, H.; Yoon, H. Exfoliation of 2D materials for energy and environmental applications. Chemistry. 2020. 26(29), 6360-6401.

[24] Glavin, N.R.; Rao, R.; Varshney, V.; Bianco, A.; Apte, A.; Roy, A.; Ringe, E.; Ajayan, P.M. Emerging applications of elemental 2D materials. Adv. Mater. 2020. 32(7), 1904302.

[25] Kurapati, R.; Kostarelos, K.; Prato, M.; Bianco, A. Biomedical uses for 2D materials beyond graphene: current advances and challenges ahead. Adv. Mater. 2016. 28(29), 6052-6074.

[26] Liu, X.; Hersam, M.C. Borophene-graphene heterostructures. Sci. Adv. 2019. 5 (10), 6444.

[27] Kawai, S.; Saito, S.; Osumi, S.; Yamaguchi, S.; Foster, A.S.; Spijker, P.; Meyer, E. Atomically controlled substitutional boron-doping of graphene nanoribbons. Nat. Commun. 2015. 6, 8098.

[28] Riyanto; Sahroni, I.; Bindumadhavan, K.; Chang, P.Y.; Doong, R.A. Boron doped graphene quantum structure and $\mathrm{MoS}_{2}$ nanohybrid as anode materials for highly reversible lithium storage. Front Chem. 2019. 7, 116.

[29] Osumi, S.; Saito, S.; Dou, C.; Matsuo, K.; Kume, K.; Yoshikawa, H.; Awaga, K.; Yamaguchi, S. Boron-doped nanographene: ewis acidity, redox properties, and battery electrode performance. Chem. Sci. 2016. 7(1), 219-227.

[30] Jeong, R.H.; Lee, J.W.; Kim, D.I.; Yang, J.W.; Park, S.; Boo, J.H. Black phosphorus-molybdenum disulphide 2D nanocomposite with broad light absorption and high stability for methylene blue decomposition photocatalyst. Nanotechnology. 2020. 31(15), 155704.

[31] Afzal, A.M.; Javed, Y.; Shad, N.A.; Iqbal, M.Z.; Dastgeer, G.; Sajid, M.M.; Mumtaz, S. Tunneling-based rectification and photoresponsivity in black phosphorus/ hexagonal boron nitride/rhenium diselenide van der Waals heterojunction diode. Nanoscale. 2020. 12(5), 3455-3468.

[32] Liu, F.; Cao, R.; Rong, S.; Zhang, P. Tungsten doped manganese dioxide for efficient removal of gaseous formaldehyde at ambient temperatures. Mater. Des. 2018. 149, 165-172.

[33] Liu, J.; Du, P.; Liu, T.; Córdova Wong, B.J.; Wang, W.; Ju, H.; Lei, J. A black phosphorus/manganese dioxide nanoplatform: Oxygen self-supply monitoring, photodynamic therapy enhancement and feedback. Biomaterials. 2019. 192, 179188. 
[34] Liu, Y.; Peng, J.; Wang, S.; Xu, M.; Gao, M.; Xia, T.; Weng, J.; Xu, A.; Liu, S. Molybdenum disulfide/graphene oxide nanocomposites show favorable lung targeting and enhanced drug loading/tumor-killing efficacy with improved biocompatibility. NPG Asia Mater. 2018. 10, 458. nanoparticles decorated graphene oxide nanosheets with enhanced peroxidase-like activity for electrochemical cancer cell detection and targeted therapeutics. Mater. Sci. Eng. C Mater. Biol. Appl. 2019. 99, 1374-1383.

[36] Musselman, K.P.; Ibrahim, K.H.; Yavuz, M. Research Update: Beyond graphene-Synthesis of functionalized quantum dots of 2D materials and their applications. APL Materials. 2018. 6, 120701.

[37] Hizir, M.S.; Nandu, N.; Yigit, M.V. Homologous miRNA Analyses Using a Combinatorial Nanosensor Array with Two-Dimensional Nanoparticles. Anal Chem. 2018. 90(10), 6300-6306.

[38] Cai, R.; Yang, D.; Lin, K.; Lyu, Y.; Zhu, B.; He, Z.; Zhang, L.; Kitamura,Y.; Qiu, L.; Chen, X.; Zhao, Y.; Chen, Z.; Tan, W. Generalized Preparation of TwoDimensional Quasi-nanosheets via Self-assembly of Nanoparticles. J Am Chem Soc. 2019. 141(4), 1725-1734.

[39] Novoselov, K.S.; Geim, A.K.; Morozov, S.V.; Jiang, D.; Zhang, Y.; Dubonos, S.V.; Grigorieva1, I.V.; Firsov, A.A. Electric field effect in atomically thin carbon films. Science. 2004. 306, 666-669.

[40] Novoselov, K.S.; Falko, V.I.; Colombo, L.; Gellert, P.R.; Schwab, M.G.; Kim, K. A roadmap for graphene. Nature. 2012. 490, 192-200. doi: 10.1038/nature11458.

[41] Kostarelos, K.; Novoselov, K.S. Exploring the interface of graphene and biology. Science. 2014. 344, 261-263.

[42] Pang, S.; Hernandez, Y.; Feng, X.; Müllen, K. Graphene as transparent electrode material for organic electronics. Adv. Mater. 2011. 23, 2779-2795.

[43] Loh, K.P.; Bao, Q.; Eda, G.; Chhowalla, M. Graphene oxide as a chemically tunable platform for optical applications. Nat. Chem. 2010. 2, 1015-1024.

[44] Wei, W.; He, T.; Teng, X.; Wu, S.; Ma, L.; Zhang, H.; Ma, J.; Yang, Y.; Chen, H.; Han, Y.; Sun, H.; Huan, L. Nanocomposites of graphene oxide and upconversion rare-earth nanocrystals with superior optical limiting performance. Small. 2012. 8, 2271-2276. 
[45] Stankovich, S.; Dikin, D.A.; Dommett, H.B.G.H.B.; Kohlhaas, K.M.; Zimney,

E.J.; Stach, E.A.; Piner, R.D.; Nguyen, S.T.; Ruoff, R.S. Graphene-based composite materials. Nature. 2006. 442, 282-286.

[46] Shen, J., Zhu, Y.; Yang, X.; Li, C. Graphene quantum dots: emergent nanolights for bioimaging, sensors, catalysis and photovoltaic devices. Chem. Commun. 2012. 48, 3686-3699.

[47] Wick, P.; Louw-Gaume, A.E.; Kucki, M.; Krug, H.F.; Kostarelos, K.; Fadeel, B.; Dawson, K.A.; Salvati, A.; Vázquez, E.; Ballerini, L.; Tretiach, M.; Benfenati, F.; Flahaut, E.; Gauthier; L.; Prato, M.; Bianco, A. A classification framework for graphene-based materials. Angew. Chem. Int. Ed. 2014. 53(30), 7714-7718. [48] Bianco, A.; Cheng, H.M.; Enoki, T.; Gogotsi, Y.; Hurt, R.H.; Koratkar, N.; Kyotani, T.; Monthioux, M.; Park, C.R.; Tascon, J.M.D.; Zhang, J. All in the graphene family-A recommended nomenclature for two-dimensional carbon materials. Carbon. 2013. 65, 1-6.

[49] Morozov, S.V.; Novoselov, K.S.; Jiang, D.; Firsov, A.A.; Dubonos, S.V.; Geim. A.K. Two-dimensional electron and hole gases at the surface of graphite. Phys. Rev. B. 2005. 72, 201401.

[50] Balandin, A. Thermal properties of graphene and nanostructured carbon materials. Nat. Mat. 2011. 10, 569.

[51] León, V.; González-Domínguez, J.M.; Fierro, J.L.G.; Prato, M.; Vázquez, E. Production and stability of mechanochemically exfoliated graphene in water and culture media. Nanoscale. 2016. 8, 14548-14555.

[52] Li, Y.; Liu, Y.; Fu, Y.; Wei, T.; Le Guyader, L.; Gao, G.; Liu, R.S.; Chang, Y.Z.; Chen, $C$. The triggering of apoptosis in macrophages by pristine graphene through the MAPK and TGF-beta signaling pathways. Biomaterials. 2012. 33, 402-411.

[53] Duan, G.; Zhang, Y.; Luan, B.; Weber, J.K.; Zhou, R.W.; Yang, Z.; Zhao, L.; Xu, J.; Luo, J.; Zhou, R. Graphene-induced pore formation on cell membranes. Sci. Rep. 2017. 7, 42767.

[54] Zhou, H.; Zhao, K.; Li, W.; Yang, N.; Liu, Y.; Chen, C.; Wei, T. The interactions between pristine graphene and macrophages and the production of cytokines/ chemokines via TLR- and NF-kappaB-related signaling pathways. Biomaterials. 2012. 33, 6933-6942. 
[55] Lin, H.; Ji, D.K.; Lucherelli, M.A.; Reina, G.; Ippolito, S.; Samorì, P.; Bianco, A. Comparative effects of graphene and molybdenum disulfide on human macrophage toxicity. Small. 2020. 16(35), e2002194.

[56] Ruiz, A.; Lucherelli, M.A.; Murera, D.; Lamon, D.; Ménard-Moyon, C.; Bianco, A. Toxicological evaluation of highly water dispersible few-layer graphene in vivo. Carbon. 2020. 170, 347-360.

[57] Cristo, L.D., McCarthy, S.; Paton, K.; Movia, D.; Prina-Mello, A. Interplay between oxidative stress and endoplasmic reticulum stress mediated- autophagy in unfunctionalised few-layer graphene-exposed macrophages. 2D Mater. 2018. 5, 045033.

[58] Malanagahalli, S.; Murera, D.; Martín, C.; Lin, H.; Wadier, N.; Dumortier, H.; Vázquez, E.; Bianco, A. Few layer graphene does not affect cellular homeostasis of mouse macrophages. Nanomaterials. 2020. 10, 228.

[59] McIntyre, J.; Verma, N.K.; Smith, R.J.; Moore, C.; Nerl, H.; McEvoy, N.; Berner, N.; McGovern, I.; Khan, U.; Lyons, P.; O'Neill, L.; Nicolosi, V.; Duesberg, G.S.; Byrne, H.J.; Colemanc, J.; Volkov, Y. A comparison of catabolic pathways induced in primary macrophages by pristine single walled carbon nanotubes and pristine graphene. RSC Adv. 2016. 6, 65299.

[60] Lebre, F.; Hanlon, D.; Boland, J.B.; Coleman, J.; Lavelle, E.C. Exfoliation in endotoxin-free albumin generates pristine graphene with reduced inflammatory properties. Adv. Biosys. 2018. 2(12), 1800102.

[61] Cicuéndez, M.; Fernandes, M.; Ayán-Varelac, M.; Oliveira, H.; José-Feito, M.; Diez-Orejas, R.; Paredes, J.I.; Villar-Rodil, S.; Vila, M.; Portolés, M.T.; Duarte. I.F. Macrophage inflammatory and metabolic responses to graphene-based nanomaterials differing in size and functionalization. Colloid. Surface. B. 2020. 186, 110709.

[62] Sasidharan, A.L.S.; Panchakarla, L.S.; Chandran, P.; Menon, D.; Nair, S.; Raob, C.N.R.; Koyakutty, M. Differential nano-bio interactions and toxicity effects of pristine versus functionalized graphene. Nanoscale. 2011. 3, 2461-2464.

[63] Sasidharan, A.L.S.; Panchakarla, L.S.; Sadanandan, A.R.; Ashokan, A.; Chandran, P.; Girish, C.M.; Menon, D.; Nair, S.V.; Rao, C.N.R.; Koyakutty, M. Hemocompatibility and macrophage response of pristine and functionalized graphene. Small. 2012. 8(8), 1251-1263. 
[64] Girish, C.M.; Sasidharan, A.; Gowd, G.S.; Nair, S.; Koyakutty, M. Confocal raman imaging study showing macrophage mediated biodegradation of graphene in vivo. Adv. Healthcare Mater. 2013. 2, 1489-1500.

[65] Sasidharan, A.; Swaroop, S.; Koduri, C.K.; Madathil-Girish, C.; Chandran, P.; Comparative in vivo toxicity, organ biodistribution and immune response of pristine, carboxylated and PEGylated few-layer graphene sheets in Swiss albino mice: A three-month study. Carbon. 2015. 95, 511-524.

[66] Lawal, A.T. Graphene-based nano composites and their applications. A review. Biosens. Bioelectron. 2019. 141, 111384.

[67] Xia, M.Y.; Xie, Y.; Yu, C.H.; Chen, G.Y.; Li, Y.H.; Zhang, T.; Peng, Q. Graphene-based nanomaterials: The promising active agents for antibioticsindependent antibacterial applications. J. Control. Release. 2019. 307, 16-31. [68] De Melo-Diogo, D.; Lima-Sousa, R.; Alves, C.G.; Correia, I.J. Graphene family nanomaterials for application in cancer combination photothermal therapy. Biomater. Sci. 2019. 7, 3534-3551.

[69] Bullo, S.; Buskaran, K.; Baby, R.; Dorniani, D.; Fakurazi, S.; Hussein, M.Z. Dual drugs anticancer nanoformulation using graphene oxide-PEG as nanocarrier for protocatechuic acid and chlorogenic acid. Pharm. Res. 2019. 36, 91.

[70] Tiwari, H.; Karki, N.; Pal, M.; Basak, S.; Verma, R.K.; Bal, R.; Kandpal, N.D.; Bisht, G.; Sahoo, N.G. Functionalized graphene oxide as a nanocarrier for dual drug delivery applications: The synergistic effect of quercetin and gefitinib against ovarian cancer cells. Colloid. Surface. B. 2019. 178, 452-459.

[71] Yang, K.; Feng, L.; Liu, Z. The advancing uses of nano-graphene in drug delivery. Expert Opin. Drug Deliv. 2015. 12, 601-612.

[72] Muthoosamy, K.; Bai, R.G.; Manickam, S. Graphene and graphene oxide as a docking station for modern drug delivery system. Curr. Drug Deliv. 2014. 11, 701718.

[73] Ye, S.; Shao, K.; Li, Z.; Guo, N.; Zuo, Y.; Li, Q.; Lu, Z.; Chen, L.; He, Q.; Han, H. Antiviral activity of graphene oxide: how sharp edged structure and charge matter. ACS Appl. Mater. Interfaces. 2015. 7(38), 21571-21579.

[74] Menaa, F.; Abdelghani, A.; Menaa, B. Graphene nanomaterials as biocompatible and conductive scaffolds for stem cells: impact for tissue engineering and regenerative medicine. J. Tissue Eng. Regen. Med. 2015. 9, 1321-1338. 
[75] Bartelmess, J.; Quinn, S.J.; Giordani, S. Carbon nanomaterials: multi-functional agents for biomedical fluorescence and Raman imaging. Chem. Soc. Rev. 2015. 44, 4672-4698.

[76] Wang, Z.Y.; Dai, Z. Carbon nanomaterial-based electrochemical biosensors: an overview. Nanoscale. 2015. 7, 6420-6431.

[77] Zhu, J.; Xu, M.; Gao, M.; Zhang, Z.; Xu, Y.; Xia, T.; Liu, S. Graphene oxide induced perturbation to plasma membrane and cytoskeletal meshwork sensitize cancer cells to chemotherapeutic agents. ACS Nano. 2017. 11, 2637-2651.

[78] Stern, S.T.; Adiseshaiah, P.P.; Crist, R.M. Autophagy and lysosomal dysfunction as emerging mechanisms of nanomaterial toxicity. Part. Fibre Toxicol. 2010. 9, 20.

[79] Cohignac, V.; Landry, M.J.; Boczkowski, J.; Lanone, S. Autophagy as a possible underlying mechanism of nanomaterial toxicity. Nanomaterials. 2014. 4, 548-582. [80] Chen, G.Y.; Yang, H.J.; Lu, C.H.; Chao, Y.C.; Hwang, S.M.; Chen, C.L.; Lo, K.W.; Sung, L.Y.; Luo, W.Y.; Tuan, H.Y.; Hu, Y.C. Simultaneous induction of autophagy and toll-like receptor signaling pathways by graphene oxide.

Biomaterials. 2012. 33, 6559-6569.

[81] Wan, B.; Wang, Z.X.; Lv, Q.Y.; Dong, P.X.; Zhao, L.X.; Yang, Y.; Guo, L.H. Single-walled carbon nanotubes and graphene oxides induce autophagosome accumulation and lysosome impairment in primarily cultured murine peritoneal macrophages. Toxicol. Lett. 2013. 221, 118-127.

[82] Yang, X.; Yang, X.; Zhang, Y.; Lai, W.; Xiang, Z.; Tu, B.; Li, D.; Nan, X.; Chen, C.; Hu, Z.; Fang, Q. Proteomic profiling of RAW264.7 macrophage cells exposed to graphene oxide: insights into acute cellular responses. Nanotoxicology. 2019. 13(1), 35-49.

[83] Wu, Y.; Wang, F.; Wang, S.; Ma, J.; Xu, M.; Gao, M.; Liu, R.; Chen, W.; Liu, S. Reduction of graphene oxide alters its cyto-compatibility towards primary and immortalized macrophages. Nanoscale. 2018. 10, 14637-14650.

[84] Li, R.; Guiney, L.M.; Chang,C.; Mansukhani, N.D.; Ji, Z.; Wang, X.; Liao, .P.; Jiang, W.; Sun, B.; Hersam, M.; Nel, A.; Xia, T. Surface oxidation of graphene oxide determines membrane damage, lipid peroxidation, and cytotoxicity in macrophages in a pulmonary toxicity model. ACS Nano. 2018. 12, 1390-1402. [85] Qu, G.; Liu, S.; Zhang, S.; Wang, L.; Wang, X.; Sun, B.; Yin, N.; Gao, X.; Xia, T.; Chen, J.; Jiang, G. Graphene oxide induces toll-like receptor 4 (TLR4)dependent necrosis in macrophages. ACS Nano. 2013. 7, 5732-5745. 
[86] Diez-Orejas, R.; Feito, M.J.; Cicuéndez, M.; Rojo, J.M.; Portolés, M.T.

Differential effects of graphene oxide nanosheets on Candida albicans phagocytosis by murine peritoneal macrophages. J. Colloid Interface Sci. 2018. 512, 665-673.

[87] Matesanz, C.; Vila, M.; Feito, M.J.; Linares, J.; Gonçalves, G.; Vallet-Regí, M.; Marques, P.A.A.P.; Portolés, M. The effects of graphene oxide nanosheets localized on F-actin filaments on cell-cycle alterations. Biomaterials. 2013. 34, 1562-1569. [88] Kalman, J.; Merino, C.; Férnandez-Cruz, M.L.; Navas, J. Usefulness of fish cell lines for the initial characterization of toxicity and cellular fate of graphene-related materials (carbon nanofibers and graphene oxide). Chemosphere. 2019. 218, 347358.

[89] Linares, J.; Matesanz, M.; Vila, M.; Feito, M.J.; Gonçalves, G.; Vallet-Regí, M.; Marques, P.; Portolés, M.T. Endocytic mechanisms of graphene oxide nanosheets in osteoblasts, hepatocytes and macrophages. ACS Appl. Mater. Interfaces. 2014. 6, 3697-13706.

[90] Mu, Q.; Su, G.; Li, L.; Gilbertson, B.O.; Yu, L.H.; Zhang, Q.; Sun, Y.; Yan, B. Size-dependent cell uptake of protein-coated graphene oxide nanosheets. ACS Appl. Mater. Interfaces. 2012. 4, 2259-2266.

[91] Russier, J.; Treossi, E.; Scarsi, A.; Perrozzi, F.; Dumortier, H.; Ottaviano, L.; Meneghetti, M.; Palermo, V.; Bianco, A. Evidencing the mask effect of graphene oxide: a comparative study on primary human and murine phagocytic cells. Nanoscale. 2013. 5, 11234.

[92] Vila, M.; Portolés, M.; Marques, P.; Feito, M.J.; Matesanz, M.; RamírezSantillán, C.; Gonçalves, G.; Cruz, S.A.; Nieto, A.; Vallet-Regí, M. Cell uptake survey of pegylated nanographene oxide. Nanotechnology. 2012. 23, 465103. [93] Zhang, H.; Peng, C.; Yang, J.; Lv, M.; Liu, R.; He, D.; Fan, C.; Huang, Q. Uniform ultrasmall graphene oxide nanosheets with low cytotoxicity and high cellular uptake. ACS Appl. Mater. Interfaces. 2013. 5(5), 1761-1767.

[94] Ma, J.; Liu, R.; Wang, X.; Liu, Q.; Chen, Y.; Valle, R.P.; Zuo, Y.Y.; Xia, T.; Liu, S. Crucial role of lateral size for graphene oxide in activating macrophages and stimulating pro-inflammatory responses in cells and animals. ACS Nano. 2015. 9 , 10498-10515.

[95] Rodrigues, A.F.; Newman, L.A.; Jasim, D.A.; Vacchi, I.A.; Ménard-Moyon, C.; Crica, L.E.; Bianco, A.; Kostarelos, K.; Bussy, C. Immunological impact of 
graphene oxide sheets in the abdominal cavity is governed by surface reactivity. Arch. Toxicol. 2018. 92, 3359-3379.

[96] Yue, H.; Wei, W.; Yue, Z.; Wang, B.; Luo, N.; Gao, Y.; Ma, D.; Ma, G.; Su, Z. The role of the lateral dimension of graphene oxide in the regulation of cellular responses. Biomaterials. 2012. 33, 4013-4021.

[97] Mendes, R.G.; Koch, B.; Bachmatiuk, A.; Ma, X.; Sánchez, S.; Damm, C.; Schmidt, O.; Gemming, T.; Eckert, J.; Rümmeli, M. A size dependent evaluation of the cytotoxicity and uptake of nanographene oxide. J. Mater. Chem. B. 2015. 3, $2522-2529$.

[98] Luo, N.; Ni, D.; Yue, H.; Wei, W.; Ma, G. Surface-engineered graphene navigate divergent biological outcomes toward macrophages. ACS Appl. Mater. Interfaces. 2015. 7, 5239-5247.

[99] Wang, B.; Su, X.; Liang, J.; Yang, L.; Hu, Q.; Shan, X.; Wan, J.; Hu, Z.

Synthesis of polymer-functionalized nanoscale graphene oxide with different surface charge and its cellular uptake, biosafety and immune responses in Raw264.7 macrophages. Mat. Sci. Eng. C-Mater. 2018. 90, 514-522.

[100] Reina, G.; Ruiz, A.; Murera, D.; Nishina, Y.; Bianco, A. "Ultramixing”: a simple and effective method to obtain controlled and stable dispersions of graphene oxide in cell culture media. ACS Appl. Mater. Interfaces. 2019. 11, 7695-7702. [101] Yue, Z.G.; Wei, W.; Lv, P.; Yue, H.; Wang, L.; Su, Z.; Ma, G. Surface charge affects cellular uptake and intracellular trafficking of chitosan-based nanoparticles. Biomacromolecules. 2011. 12, 2440-2446.

[102] Feito, M.J.; Vila, M.; Matesanz, M.; Linares, J.; Gonçalves, G.; Marques, P.; Vallet-Regí, M.; Rojo, J.M.; Portolés, M. 2014. In vitro evaluation of graphene oxide nanosheets on immune function. J. Colloid. Interf. Sci. 2014. 432, 221-228. [103] Kim, H.; Kim, J.; Lee, M.; Choi, H.C.; Kim, W.J. Stimuli-regulated enzymatically degradable smart graphene-oxide-polymer nanocarrier facilitating photothermal gene delivery. Adv. Healthcare Mater. 2016. 5, 1918-1930. [104] Pi, J.; Shen, L.; Shen, H.; Yang, E.; Wang, W.; Wang, R.; Huang, D.; Lee, B.; Hu, C.; Chen, C.Y.; Jin, H.; Cai, J.; Zeng, G.; Chen, Z.W. Mannosylated graphene oxide as macrophage-targeted delivery system for enhanced intracellular M.tuberculosis killing efficiency. Mat. Sci. Eng. C. 2019. 103, 109777. [105] Yan, J.; Chen, L.; Huang, C.; Lung, S.C.; Yang, L.; Wang, W.; Lin, P.; Suo, G.; Lin, C. Consecutive evaluation of graphene oxide and reduced graphene oxide 
nanoplatelets immunotoxicity on monocytes. Colloid. Surface. B. 2017. 153, 300309.

[106] Lategan, K.; Alghadi, H.; Bayati, M.; de Cortalezzi, M.M.F.; Pool, E.J. Effects of graphene oxide nanoparticles on the immune system biomarkers produced by RAW264.7 and human whole blood cell cultures. Nanomaterials. 2018. 8, 125. [107] Yang, X.; Yang, Q.; Zheng, G.; Han, S.; Zhao, F.; Hu, Q.; Fu, Z. Developmental neurotoxicity and immunotoxicity induced by graphene oxide in zebrafish embryos. Environ. Toxicol. 2019. 34, 415-423.

[108] Hoyle, C.; Rivers-Auty, J.; Lemarchand, E.; Vranic, S.; Wang, E.; Buggio, M.; Rothwell, N.; Allan, S.; Kostarelos, K.; Brough, D. Small, thin graphene oxide is anti-inflammatory activating nuclear factor erythroid 2-related factor 2 via metabolic reprogramming. ACS Nano. 2018. 12, 11949-11962.

[109] Mukherjee, S.P.; Kostarelos, K.; Fadeel, B. Cytokine profiling of primary human macrophages exposed to endotoxin-free graphene oxide: size-independent NLRP3 inflammasome activation. Adv. Healthcare Mater. 2018. 7, 1700815.

[110] Luo, N.; Weber, J.K.; Wang, S.; Luan, B.; Yue, H.; Xi, X.; Du, J.; Yang, Z.; Wei, W.; Zhou, R.; Ma, G. PEGylated graphene oxide elicits strong immunological responses despite surface passivation. Nat. commun. 2017. 8, 14537.

[111] Diez-Orejas, R.; Feito, M.J.; Cicuéndez, M.; Casarrubios, L.; Rojo, J.M.; Portolés, M.T. Graphene oxide nanosheets increase Candida albicans killing by proinflammatory and reparative peritoneal macrophages. Colloid. Surface. B. 2018. $171,250-259$.

[112] Han, J.; Kim, Y.; Lim, M.; Kim, H.Y.; Kong, S.; Kang, M.; Choo, Y.W.; Jun, J.; Ryu, S.; Jeong, H.; Park, J.; Jeong, G.J.; Lee, J.C; Eom, G.H.; Y.; Kim, B Dual roles of graphene oxide to attenuate inflammation and elicit timely polarization of macrophage phenotypes for cardiac repair. ACS Nano. 2018. 12, 1959-1977.

[113] Silvestrov, P.G.; Efetov, K. Quantum dots in graphene. Phys. Rev. Lett. 2007. 98, 016802.

[114] Ponomarenko, L.; Schedin, F.; Katsnelson, M.; Yang, R.; Hill, E.H.; Novoselov, K.; Geim, A.K. Chaotic dirac billiard in graphene quantum dots. Science. 2008. 320, $356-358$.

[115] Li, L.; Wu, G.; Yang, G.; Peng, J.; Zhao, J.; Zhu, J. Focusing on luminescent graphene quantum dots: current status and future perspectives. Nanoscale. 2013. 5, 4015-4039. 
[116] Gupta, V.; Chaudhary, N.; Srivastava, R.; Sharma, G.D.; Bhardwaj, R.; Chand,

Chem. Soc. 2011. 133, 9960-9963.

[117] Sun, H.; Gao, N.; Dong, K.; Ren, J.; Qu, X. Graphene quantum dots-band-aids used for wound disinfection. ACS Nano. 2014. 8, 6202-6210.

[118] Ristic, B.Z.; Milenkovic, M.M.; Dakić, I.; Todorovic-Markovic, B.;

Milosavljević, M.; Budimir, M.D.; Paunović, V.; Dramićanin, M.; Marković, Z.;

Trajkovic, V. Photodynamic antibacterial effect of graphene quantum dots.

Biomaterials. 2014. 35, 4428-4435.

[119] Jiang, F.; Chen, D.; Li, R.; Wang, Y.; Zhang, G.; Li, S.; Zheng, J.; Huang, N.; Gu, Y.; Wang, C.; Shu, C. Eco-friendly synthesis of size-controllable aminefunctionalized graphene quantum dots with antimycoplasma properties. Nanoscale. 2013. 5, 1137-1142.

[120] Sun, X.; Liu, Z.; Welsher, K.; Robinson, J.; Goodwin, A.; Zaric, S.; Dai, H. Nano-graphene oxide for cellular imaging and drug delivery. Nano Res. 2008. 1, 203-212.

[121] Schroeder, K.L.; Goreham, R.V.; Nann, T. Graphene quantum dots for theranostics and bioimaging. Pharm. Res. 2016. 33, 2337-2357.

[122] Hwang, E.; Hwang, H.M.; Shin, Y.; Yoon, Y.; Lee, H.; Yang, J.; Bak, S.; Lee, H. Chemically modulated graphene quantum dot for tuning the photoluminescence as novel sensory probe. Sci. Rep. 2016. 6, 39448.

[123] Qian, Z.S.; Shan, X.Y.; Chai, L.J.; Ma, J.J.; Chen, J.R.; Feng, H. DNA nanosensor based on biocompatible graphene quantum dots and carbon nanotubes. Biosens. Bioelectron. 2014. 60(15), 64-70.

[124] Liu, Z.; Robinson, J.; Sun, X.; Dai, H. PEGylated Nanographene Oxide for Delivery of Water-Insoluble Cancer Drugs. J. Am. Chem. Soc. 2008. 130, 1087610877.

[125] Iannazzo, D.; Ziccarelli, I.; Pistone, A. Graphene quantum dots: multifunctional nanoplatforms for anticancer therapy. J. Mater. Chem. B. 2017. 5, 6471-6489.

[126] Joshi, P.N.; Kundu, S.; Sanghi, S.; Sarkar, D. Graphene quantum dots-from emergence to nanotheranostic applications. In: Sezer, A.D. (Ed.), Smart Drug Delivery System. Intech. Open Limited, London. 2016.

[127] Qin, Y.; Zhou, Z.; Pan, S.; He, Z.; Zhang, X.; Qiu, J.; Duan, W.; Yang, T.; Zhou, S. Graphene quantum dots induce apoptosis, autophagy, and inflammatory 
response via p38 mitogen-activated protein kinase and nuclear factor-kappaB mediated signaling pathways in activated THP-1 macrophages. Toxicology. 2015. $327,62-76$.

[128] Volarevic, V.; Paunović, V.; Marković, Z.; Markovic, B.S.; MisirkicMarjanovic, M.; Todorovic-Markovic, B.M.; Bojic, S.; Vucicevic, L.M.; Jovanović, S.; Arsenijević, N.; Holclajtner-Antunovic, I.; Milosavljevic, M.; Dramicanin, M.; Kravic-Stevovic, T.; Ciric, D.; Lukic, M.L.; Trajkovic, V. Large graphene quantum dots alleviate immune-mediated liver damage. ACS Nano. 2014. 8, 12098-12109.

[129] Oh, B.; Lee, C.H. Development of thiolated-graphene quantum dots for regulation of ROS in macrophages. Pharm. Res. 2016. 33, 2736-2747.

[130] Oh, B.; Lee, Y.; Fu, M.; Lee, C.H. Computational analysis on down-regulated images of macrophage scavenger receptor. Pharm. Res. 2017. 34, 2066-2074.

[131] Liu, F.; Jang, M.; Ha, H.D.; Kim, J.; Cho, Y.; Seo, T.S. Facile synthetic method for pristine graphene quantum dots and graphene oxide quantum dots: origin of blue and green luminescence. Adv. Mater. 2013. 25, 3657-3662.

[132] Goreham, R.; Schroeder, K.L.; Holmes, A.; Bradley, S.J.; Nann, T.

Demonstration of the lack of cytotoxicity of unmodified and folic acid modified graphene oxide quantum dots, and their application to fluorescence lifetime imaging of HaCaT cells. Microchim. Acta. 2018. 185, 128.

[133] Xu, L.; Dai, Y.; Wang, Z.; Zhao, J.; Li, F.; White, J.C.; Xing, B. Graphene quantum dots in alveolar macrophage: uptake-exocytosis, accumulation in nuclei, nuclear responses and DNA cleavage. Part. Fibre Toxicol. 2018. 15(1), 45.

[134] Xu, L.; Zhao, J.; Wang, Z. Genotoxic response and damage recovery of macrophages to graphene quantum dots. Sci. Total Environ. 2019. 664, 536-545.

[135] Kumar, R.S.; Shakambari, G.; Ashokkumar, B.; Nelson, D.J.; John, S.A.; Varalakshmi, P. Nitrogen-doped graphene quantum dot-combined sodium 10amino-2-methoxyundecanoate: studies of proinflammatory gene expression and live cell Imaging. ACS Omega. 2018. 3, 11982-11992.

[136] Chhowalla, M.; Shin, H.; Eda, G.; Li, L.; Loh, K.P.; Zhang, H. The chemistry of two-dimensional layered transition metal dichalcogenide nanosheets. Nat. Chem. 2013. $5,263$.

[137] Miró, P.; Ghorbani-Asl, M.; Heine, T. Two dimensional materials beyond $\mathrm{MoS}_{2}$ : noble-transition-metal dichalcogenides. Angew. Chem. Int. Ed. 2014. 53, 3015. 
[138] Mitrano, D.M.; Motellier, S.; Clavaguera, S.; Nowack, B. Review of nanomaterial aging and transformations through the life cycle of nano-enhanced products. Environ. Int. 2015. 77, 132-147.

[139] [IMA] International Molybdenum Association. Molybdenum Uses. [accessed 7 Apr 2020]. https://www.imoa.info/molybdenum-uses/molybdenum-chemistryuses/molybdenum-chemistry-uses.php.

[140] [ATSDR] US Agency for Toxic Substances and Disease Registry. Toxicological Profile for Molybdenum. Apr 2017 Version. [accessed 7 Apr 2020]. https://www.atsdr.cdc.gov/ToxProfiles/tp212.pdf.

[141] Turnlund, J.R.; Keyes, W.; Peiffer, G. Molybdenum absorption, excretion, and retention studied with stable isotopes in young men at five intakes of dietary molybdenum. Am. J. Clin. Nutr. 1995. 62(4),790-796.

[142] [US DRI] US Dietary Reference Intakes for Vitamin A, Vitamin K, Arsenic, Boron, Chromium, Copper, Iodine, Iron, Manganese, Molybdenum, Nickel, Silicon, Vanadium, and Zinc. 2001. [accessed 13 Apr 2020]. http://nap.edu/10026.

[143] Jakobsen, S.S.; Larsen, A.; Stoltenberg, M.; Bruun, J.; Søballe, K. Effects of ascast and wrought Cobalt-Chrome-Molybdenum and Titanium-AluminiumVanadium alloys on cytokine gene expression and protein secretion in J774A.1 macrophages. Eur. Cell Mater. 2007. 14, 45-54.

[144] Kanaji, A.; Caicedo, M.S.; Virdi, A.S.; Sumner, D.R.; Hallab, N.J.; Sena, K. Co-Cr-Mo Alloy Particles Induce Tumor Necrosis Factor Alpha Production in MLO-Y4 Osteocytes: A Role for Osteocytes in Particle Induced Inflammation. Bone. 2009. 45(3), 528-533.

[145] Bijukumar, D.R.; Segu, A.; Souza, J.; Li, X.; Barba, M.; Mercuri, L.; Jacobs, J.J.; Mathew, M.T. Systemic and local toxicity of metal debris released from hip prostheses: A review of experimental approaches. Nanomedicine. 2018. 14(3), 951963.

[146] Lin, H.Y.; Bumgardner. J.D. In vitro biocorrosion of Co-Cr-Mo implant alloy by macrophage cells. J. Orthop. Res. 2004. 22(6), 1231-1236.

[147] Caicedo, M.S.; Desai, R.; McAllister, K.; Reddy, A.; Jacobs, J.J.; Hallab, N.J. Soluble and particulate Co-Cr-Mo alloy implant metals activate the Inflammasome danger signaling pathway in human macrophages: a novel mechanism for implant debris reactivity. J. Orthop. Res. 2009. 27(7), 847-854. 
[148] Caicedo, M.S.; Samelko, L.; McAllister, K.; Jacobs, J.J.; Hallab, N.J. Increasing both CoCrMo-alloy particle size and surface irregularity induces increased macrophage inflammasome activation in vitro potentially through lysosomal destabilization mechanisms. J. Orthop. Res. 2013. 31(10), 1633-1642.

[149] Jamsen, E.; Pajarinen, J.; Kouri, V.P.; Rahikkala, A.; Goodman, S.; Manninen, M.; Nordström, D.; Eklund, K.; Nurmi, K. Tumor necrosis factor primes and metal particles activate the NLRP3 inflammasome in human primary macrophages. Acta Biomater. 2020. 108, 347-357.

[150] Wang, X.; Mansukhani, N.D.; Guiney, L.M.; Ji, Z.; Chang, C.H.; Wang, M.; Liao, Y.; Song, T.; Sun, B.; Li, R.; Xia, T.; Hersam, M.; Nel, A. Differences in the toxicological potential of two-dimensional versus aggregated molybdenum disulfide in the lung. Small. 2015. 11(38), 5079-5087.

[151] Chng, E.L.K.; Sofer, Z.; Pumera, M. $\mathrm{MoS}_{2}$ exhibits stronger toxicity with increased exfoliation. Nanoscale. 2014. 6, 14412-14418. doi: 10.1039/c4nr04907a. [152] Song, C.; Li, Z.; Chen, Y.; Zheng, C.; Hu, N.; Guo, C. Macrophage-engulfed $\mathrm{MoS}_{2}$ for active targeted photothermal therapy. New J. Chem. 2019. 43, 1838. [153] Hao, J.; Song, G.; Liu, T.; Yi, X.; Yang, K.; Cheng, L.; Liu, Z. In vivo long-term biodistribution, excretion, and toxicology of PEGylated transition-metal dichalcogenides $\mathrm{MS}_{2}(\mathrm{M}=\mathrm{Mo}, \mathrm{W}, \mathrm{Ti})$ nanosheets. Adv. Sci. 2017. 4(1), 1600160. [154] Sun, G.; Yang, S.; Cai, H.; Shu, Y.; Han, Q.; Wang, B.; Li, Z.; Zhou, L.; Gao, Q.; Yin, Z. Molybdenum disulfide nanoflowers mediated anti-inflammation macrophage modulation for spinal cord injury treatment. J. Colloid. Interface Sci. 2019. $549,50-62$.

[155] Moore, C.; Harvey, A.; Coleman, J.N.; Byrne, H.; McIntyre, J. In vitro localisation and degradation of few-layer $\mathrm{MoS}_{2}$ submicrometric plates in human macrophage-like cells: a label free Raman microspectroscopic study. 2D Mater. 2020. 7, 025003.

[156] Kurapati, R.; Muzi, L.; de Garibay, A.P.R.; Russier, J.; Voiry, D.; Vacchi, I.A.; Chhowalla, M.; Bianco A. Enzymatic biodegradability of pristine and functionalized transition metal dichalcogenide $\mathrm{MoS}_{2}$ nanosheets. Adv. Funct. Mat. 2017. 27(7), 1605176.

[157] Trumbo, P.; Yates, A.; Schlicker, S.; Poos, M. Dietary reference intakes: vitamin A, vitamin K, arsenic, boron, chromium, copper, iodine, iron, manganese, 
molybdenum, nickel, silicon, vanadium, and zinc. J. Am. Diet. Assoc. 2001. 101(3), 294-301.

[158] [ATSDR] US Agency for Toxic Substances and Disease Registry. Toxicological Profile for Manganese. Sep 2012 Version. [accessed 7 Apr 2020].

https://www.atsdr.cdc.gov/toxprofiles/tp151.pdf.

[159] Aschner, M.; Erikson, K.; Dorman, D. Manganese dosimetry: species

differences and implications for neurotoxicity. Crit. Rev. Toxicol. 2005. 35(1), 1-32.

[160] Bae, J.H.; Jang, B.; Suh, S.; Ha, E.; Shin, D. Manganese induces inducible nitric oxide synthase (iNOS) expression via activation of both MAP kinase and PI3K/Akt pathways in BV2 microglial cells. Neurosci. Lett. 2006. 398(1-2), 151-154.

[161] Papp-Wallace, K.M.; Maguire, M.E. Manganese transport and the role of manganese in virulence. Annu. Rev. Microbiol. 2006. 60, 187-209.

[162] Forbes, J.R.; Gros, P. Iron, manganese, and cobalt transport by Nramp1 (Slc11a1) and Nramp2 (Slc11a2) expressed at the plasma membrane. Blood. 2003. 102(5), 1884-1892.

[163] Skebo, J.E.; Grabinski, C.; Schrand, A.; Schlager, J.; Hussain, S. Assessment of metal nanoparticle agglomeration, uptake, and interaction using high-illuminating system. Int. J. Toxicol. 2007. 26(2), 135-141.

[164] Kumar, S.; Adjei, I.M.; Brown, S.B.; Liseth, O.; Sharma, B. Manganese dioxide nanoparticles protect cartilage from inflammation-induced oxidative stress.

Biomaterials. 2019. 224, 119467.

[165] Snella, M.C. Manganese dioxide induces alveolar macrophage chemotaxis for neutrophils in vitro. Toxicology. 1985. 34(2),153-159.

[166] Song, M.; Liu, T.; Shi, C.; Zhang, X.; Chen, X. Bioconjugated manganese dioxide nanoparticles enhance chemotherapy response by priming tumor-associated macrophages toward M1-like phenotype and attenuating tumor hypoxia. ACS Nano. 2016. $10(3), 3872$.

[167] Wen, W.; Song, Y.; Yan, X.; Zhu, C.; Du, D.; Wang, S.; Asiri, A.; Lin, Y. Recent advances in emerging 2D nanomaterials for biosensing and bioimaging applications. Materials Today. 2018. 21(2), 164-177.

[168] Alimohammadi, F.; Gh, M.S.; Attanayake, N.H.; Thenuwara, A.C.; Gogotsi, Y.; Anasori, B.; Strongin, D. Antimicrobial Properties of 2D $\mathrm{MnO}_{2}$ and $\mathrm{MoS}_{2}$ Nanomaterials Vertically Aligned on Graphene Materials and $\mathrm{Ti}_{3} \mathrm{C}_{2}$ MXene. Langmuir. 2018. 34, 7192-7200. 
[169] Das, B.C.; Thapa, P.; Karki, R.; Schinke, C.; Das, S.; Kambhampati, S.; Banerjee, S.; Van Veldhuizen, P.V.; Verma, A.; Weiss, L.; Evans, T. Boron chemicals in diagnosis and therapeutics. Future Med. Chem. 2013. 5(6), 653-676.

[170] Baker, S.J.; Zhang, Y.; Akama, T.; Lau, A.; Zhou, H.; Hernandez, V.S.; Mao, W.; Alley, M.R.; Sanders, V.; Plattner, J. Discovery of a new boron-containing antifungal agent, 5-Fluoro-1,3-dihydro-1-hydroxy-2,1-benzoxaborole (AN2690), for the potential treatment of qnychomycosis. J. Med. Chem. 2006. 49(15), 4447-4450.

[171] Connolly, B.A.; Sanford, D.G.; Chiluwal, A.K.; Healey, S.E.; Peters, D.; Dimare, M.T..; Wu, W.; Liu, Y.; Maw, H.; Zhou, Y.; Li, Y.; Jin, Z.; Sudmeier, J.; Lai, J.; Bachovchin, W. Dipeptide boronic acid inhibitors of dipeptidyl peptidase IV: determinants of potency and in vivo efficacy and safety. J. Med. Chem. 2008. 51(19), 6005-6013.

[172] Morandi, S.; Morandi, F.; Caselli, E.; Shoichet, B.; Prati, F. Structure-based optimization of Cephalothin-analogue boronic acids as $\beta$-lactamase inhibitors. Bioorg. Med. Chem. 2008. 16(3), 1195-1205.

[173] Li, X.; Zhang, Y.; Liu, Y.; Ding, C.; Zhou,Y.; Li, Q.; Plattner, J.; Baker, S.; Zhang, S.; Kazmierski, W.; Wright, L.L.; Smith, G.K.; Grimes, R.M.; Crosby, R.M.; Creech, K.L.; Carballo, L.H.; Slater, M.J.; Jarvest, R.L.; Thommes, P.; Hubbard, J.A.; Convery, M.A.; Nassau, P.M.; McDowell, W.; Skarzynski, T.J.; Qian, X.; Fan, D.; Liao, L.; Ni, Z.; Pennicott, L.E.; Zou, W.; Wright, J. Novel macrocyclic HCV NS3 protease inhibitors derived from a-amino cyclic boronates. Bioorg. Med. Chem. Lett. 2010. 20(19), 5695-5700.

[174] Ting, R.; Harwig, C.; Auf dem Keller, U.; McCormick, S.; Austin, P.; Overall, C.; Adam, M.; Ruth, T.; Perrin, D. Toward $\left[{ }^{18} \mathrm{~F}\right]$-labeled aryltrifluoroborate radiotracers: in vivo positron emission tomography imaging of stable aryltrifluoroborate clearance in mice. J. Am. Chem. Soc. 2008. 130(36), 1204512055 .

[175] Moseman, R.F. Chemical disposition of boron in animals and humans. Environ. Health Perspect. 1994. 102(Suppl 7), 113-117.

[176] Sen, O.; Emanet, M.; Çulha, M. One-step synthesis of hexagonal boron nitrides, their crystallinity and biodegradation. Front. Bioeng. Biotechnol. 2018. 6, 83. [177] Falin, A.; Cai, Q.; Santos, E.; Scullion, D.; Qian, D.; Zhang, R.; Yang, Z.; Huang, S.; Watanabe, K.; Taniguchi, T.; Barnett, M.R.; Chen, Y.; Ruoff, R.S.; Li, 
L.H. Mechanical properties of atomically thin boron nitride and the role of interlayer interactions. Nat. Commun. 2017. 8, 15815.

[178] Turkoglu, M.; Şahin, I.; San, T. Evaluation of hexagonal boron nitride as a new tablet lubricant. Pharm. Dev. Technol. 2005. 10(3), 381-388.

[179] Wang, J.; Ma, F.; Liang, W.; Sun, M. Electrical properties and applications of graphene, hexagonal boron nitride (h-BN), and graphene/h-BN heterostructures. Materials Today Physics. 2017. 2, 6-34.

[180] Jugdaohsingh, R.; Pedro, L.D.; Watson, A.I.E.; Powell, J.J. Silicon and boron differ in their localization and loading in bone. Bone. Rep. 2014. 1, 9-15.

[181] Farshid, B.; Lalwani, G.; Mohammadi, M.S.; Simonsen, J.; Sitharaman, B. Boron nitride nanotubes and nanoplatelets as reinforcing agents of polymeric matrices for bone tissue engineering. J. Biomed. Mater. Res. B Appl. Biomater. 2017. 105(2), 406-419.

[182] Li, X.; Wang, X.; Zhang, J.; Hanagata, N.; Wang, X.; Weng, Q.; Ito, A.; Bando, Y.; Golberg, D. Hollow boron nitride nanospheres as boron reservoir for prostate cancer treatment. Nat. Commun. 2017. 8, 13936.

[183] Shin, K.S;, Kiyohara, H.; Matsumoto, T.; Yamada, H. Rhamnogalacturonan II from the leaves of Panax ginseng C.A. Meyer as a macrophage Fc receptor expression-enhancing polysaccharide. Carbohydr. Res. 1997. 300(3), 239-249. [184] Shin, K.S.; Kiyohara, H.; Matsumoto, T.; Yamada, H. Rhamnogalacturonan II dimers cross-linked by borate diesters from the leaves of Panax ginseng C.A. Meyer are responsible for expression of their IL-6 production enhancing activities. Carbohydrate Research. 1998. 307: 97-106.

[185] Hall, I.H.; Burnham, B.S.; Chen, S.Y.; Sood, A.; Spielvogel, B.F.; Morse, K.W. The anti-inflammatory activity of boron derivatives in rodents. Met. Based Drugs. 1995. 2(1), 1-12.

[186] Kodali, V.K.; Roberts, J.; Shoeb M.; Wolfarth, M.G.; Bishop, L.M.; Eye, T.; Barger, M.; Roach, K.A.; Friend, S.; Schwegler-Berry, D.; Chen, B.T.; Stefaniak, A.; Jordan, K.C.; Whitney, R.R.; Porter, D.W.; Erdely, A.D. Acute in vitro and in vivo toxicity of a commercial grade boron nitride nanotube mixture.

Nanotoxicology. 2017. 11(8), 1040-1058.

[187] Routray, I.; Ali, S. Boron induces lymphocyte proliferation and modulates the priming effects of lipopolysaccharide on macrophages. PLoS One. 2016. 11(3), 0150607. 
[188] Rocca, A.; Marino, A.; Del Turco, S.; Cappello, V.; Parlanti, P.; Pellegrino, M.; Golberg, D.; Mattoli, V.; Ciofani, G. Pectin-coated boron nitride nanotubes: In vitro cyto-/immune-compatibility on RAW 264.7 macrophages. Biochim. Biophys. Acta. 2016. $1860(4), 775-784$.

[189] Favron, A.; Gaufrès, E.; Fossard, F.; Phaneuf-L'Heureux, A.; Tang, N.Y.W.; Lévesque, P.L.; Loiseau, A.; Leonelli, R.; Francoeur, S. Martel, R. Photooxidation and quantum confinement effects in exfoliated black phosphorus. Nat. Mater. 2015. 14(8): 826-832.

[190] Huang, S.; Ling, X. Black phosphorus: optical characterization, properties and applications. Small. 2017. 13, 38.

[191] Zhang, T.; Wan, Y.; Xie, H.; Mu, Y.; Du, P.; Wang, D.; Wu, X.; Ji, H.; Wan, L. Degradation chemistry and stabilization of exfoliated few-layer black phosphorus in water. J. Am. Chem. Soc. 2018. 140(24), 7561-7567.

[192] Choi, J.R.; Yong, K.W.; Choi, J.Y.; Nilghaz, A.; Lin, Y.; Xu, J.; Lu, X. Black phosphorus and its biomedical applications. Theranostics. 2018. 8(4), 1005-1026. [193] Chen, J.; Wang, Q.; Liu, X.; Chen, X.; Wang, L.; Yang, W. Black phosphorus quantum dots as novel electrogenerated chemiluminescence emitters for the detection of $\mathrm{Cu}^{2+}$. Chem. Commun. 2020. 56(34), 4680-4683.

[194] Ding, H.; Tang, Z.; Zhang, L.; Dong, Y. Electrogenerated chemiluminescence of black phosphorus nanosheets and its application in the detection of $\mathrm{H}_{2} \mathrm{O}_{2}$. Analyst. 2019. 144(4), 1326-1333.

[195] Zhou, J.; Li, Z.; Ying, M.; Liu, M.; Wang, X.; Wang, X.; Cao, L.; Zhang H.; $\mathrm{Xu}, \mathrm{G}$. Black phosphorus nanosheets for rapid microRNA detection. Nanoscale. 2018. $10(11)$, $5060-5064$.

[196] Shen, Z.K.; Yuan, Y.; Wang, P.; Bai, W.; Pei, L.; Wu, S.; Yu, Z.; Zou, Z. Fewlayer black phosphorus nanosheets: a metal-free cocatalyst for photocatalytic nitrogen fixation. ACS Appl. Mater. Interfaces. 2020. 12(15), 17343-17352. [197] Huang, S.; Li, H.; Luo, H.; Yang, L.; Zhou, Z.; Xiao, Q.; Liu, Y. Conformational structure variation of human serum albumin after binding interaction with black phosphorus quantum dots. Int. J. Biol. Macromol. 2020. 146, 405-414.

[198] Zhang, H.; Han, Q.; Yin, X.; Wang, Y. Insights into the binding mechanism of two-dimensional black phosphorus nanosheets-protein associations. Spectrochim. Acta A Mol. Biomol. Spectrosc. 2020. 227, 117662. 
[199] Latiff, N.M.; Teo, W.Z.; Sofer, Z.; Fisher, A.C.; Pumera, M. The cytotoxicity of layered black phosphorus. Chemistry. 2015. 21(40), 13991-13995. [200] Zhang, X.; Zhang, Z.; Zhang, S.; Li, D.; Ma, W.; Ma, C.; Wu, F.; Zhao, Q.; Yan, Q.; Xing, B. Size effect on the cytotoxicity of layered black phosphorus and underlying mechanisms. Small. 2017. 13, 32.

[201] Qu, G.; Liu, W.; Zhao, Y.; Gao, J; Xia, T.; Shi, J.; Hu, L.; Zhou, W.; Gao, J.; Wang, H.; Luo, Q.; Zhou, Q.; Liu, S.; Yu, X.; Jiang, G. Improved biocompatibility of black phosphorus nanosheets by chemical modification. Angew. Chem. Int. Ed. Engl. 2017. 56(46), 14488-14493.

[202] Mo, J.; Xie, Q.; Wei, W.; Zhao, J. Revealing the immune perturbation of black phosphorus nanomaterials to macrophages by understanding the protein corona. Nat. Commun. 2018. 9(1), 2480.

[203] Mo, J.; Xu, Y.; Wang, X.; Wei, W.; Zhao, J. Exploiting the protein corona: coating of black phosphorus nanosheets enables macrophage polarization via calcium influx. Nanoscale. 2020. 12(3), 1742-1748.

[204] [ATSDR] US Agency for Toxic Substances and Disease Registry. Toxicological Profile for Tungsten. [accessed 13 Apr 2020].

https://www.atsdr.cdc.gov/ToxProfiles/tp186.pdf.

[205] Zheng, B.; Wang, J.; Pan, H.; Chen, H.; Ji, W.; Liao, Z.; Gong, X.; Wang, H.; Chang, J. A visual guide to gene/optothermal synergy therapy nanosystem using tungsten oxide. J. Colloid. Interface Sci. 2017. 506, 460-470.

[206] Jamal, M.; Razeeb, K.; Shao, H.; Islam, J.; Akhter, I.; Furukawa, H.; Khosla, A. Development of tungsten oxide nanoparticle modified carbon fibre cloth as flexible pH sensor. Sci. Rep. 2019. 9(1), 4659.

[207] Hou, G.; Dick, R.; Zeng, C.; Brewer, G. Antitumor and antiinflammatory effects of tetrathiotungstate in comparison with tetrathiomolybdate. Transl. Res. 2007. 149(5), 260-264.

[208] Chen, T.M.; Wu, X.; Wang, J.; Yang, G.W. 2017. WSe 2 few layers with enzyme mimic activity for high-sensitive and high-selective visual detection of glucose. Nanoscale. 2017. 9(32), 11806-11813.

[209] Chinde, S.; Grover, P. Toxicological assessment of nano and micron-sized tungsten oxide after 28 days repeated oral administration to Wistar rats. Mutat. Res. 2017. $819,1-13$. 
[210] Chinde, S.; Poornachandra, Y.; Panyala, A.; Kumari, S.I.; Yerramsetty, S.; Adicherla, H.; Grover, P. Comparative study of cyto- and genotoxic potential with mechanistic insights of tungsten oxide nano- and microparticles in lung carcinoma cells. J Appl Toxicol. 2018. 38(6): 896-913.

[211] McInturf, S.M.; Bekkedal, M.Y.V.; Wilfong, E.; Arfsten, D.P.; Chapman, G.; Gunasekar, P.G. The potential reproductive, neurobehavioral and systemic effects of soluble sodium tungstate exposure in Sprague-Dawley rats. Toxicol. Appl. Pharmacol. 2011. 254(2), 133-137.

[212] Frawley, R.P.; Smith, M.J.; White, K.L.; Elmore, S.; Herbert, R.; Moore, R.; Staska, L.; Behl, M; Hooth, M.J.; Kissling, G.E.; Germolec, D.R. 2016. Immunotoxic effects of sodium tungstate dihydrate on female $\mathrm{B} 6 \mathrm{C} 3 \mathrm{~F} 1 / \mathrm{N}$ mice when administered in drinking water. J. Immunotoxicol. 2016. 13(5), 666-675.

[213] Osterburg, A.R.; Smith, M.J.; White, K.L.; Elmore, S.A.; Herbert, R.A.; Moore, R.V.; Staska, L.M.; Behl, M.; Hooth, M.J.; Kissling, G.E.; Germolec, D.R. Oral tungstate $\left(\mathrm{Na}_{2} \mathrm{WO}_{4}\right)$ exposure reduces adaptive immune responses in mice after challenge. J. Immunotoxicol. 2014. 11(2), 148-159.

[214] Lombaert, N.; Castrucci, E.; Decordier, I.; Hummelen, P.; Kirsch-Volders, M.; Cundari, E.; Lison, D. 2013. Hard-metal (WC-Co) particles trigger a signaling cascade involving p38 MAPK, HIF-1a, HMOX1, and p53 activation in human PBMC. Arch. Toxicol. 2013. 87(2), 259-268.

[215] Zhao, J.; Bowman, L.; Magaye, R.; Leonard, S.; Castranova, V.; Ding, M. Apoptosis induced by tungsten carbide-cobalt nanoparticles in JB6 cells involves ROS generation through both extrinsic and intrinsic apoptosis pathways. Int. J. Oncol. 2013. 42(4), 1349-1359.

[216] Gao, Y.; Huang, W.; Yang, C.; Liu, Z.; Meng, H.; Yang, B.; Xu, Y.; Guo, C. Targeted photothermal therapy of mice and rabbits realized by macrophage-loaded tungsten carbide. Biomater. Sci. 2019. 7(12), 5350-5358.

[217] Armstead, A.L.; Li, B. In vitro inflammatory effects of hard metal (WC-Co) nanoparticle exposure. Int. J. Nanomedicine. 2016. 11, 6195-6206. [218] Pimenta-dos-Reis, G.; Torres, E.J.L.; Quintana, P.G.; Vidal, L.O.; Santos, B.A.F.; Lin, C.; Heise, N.; Persechini, P.M.; Schachter, J. POM-1 inhibits P2 receptors and exhibits anti-inflammatory effects in macrophages. Purinergic. Signal. 2017. 13(4), 611-627. 
[219] Dunnick, K.M.; Badding, M.A.; Schwegler-Berry, D.E.; Patete, J.M.; Koenigsmann, C.; Wong, S. S.; Leonard, S.S. The effect of tungstate nanoparticles on reactive oxygen species and cytotoxicity in Raw 264.7 mouse monocyte macrophage cells. J. Toxicol. Environ. Health A. 2014. 77(20), 1251-1268. [220] Osterburg, A.R.; Robinson, C.T.; Schwemberger, S.J.; Mokashi, V.; Stockelman, M.; Babcock, G.F. Sodium tungstate $\left(\mathrm{Na}_{2} \mathrm{WO}_{4}\right)$ exposure increases apoptosis in human peripheral blood lymphocytes. J. Immunotoxicol. 2010. 7(3), 174-182.

[221] Armstead, A.L.; Minarchick, V.C.; Porter, D.; Nurkiewicz, T.; Li, B. Acute inflammatory responses of nanoparticles in an intra-tracheal instillation rat model. PLoS One. 2015. 10(3), 0118778.

[222] Moussa, H.I.; Kim, G.; Tong, J.G.; Glerum, D.M.; Tsui, T.Y. Influence of Antimycin A, a bacterial toxin, on human dermal fibroblast cell adhesion to tungsten-silicon oxide nanocomposites. J. Exp. Nanosci. 2019. 14(1), 69-88. [223] Xu, Q.; Zhao, S.; Deng, L.; Ouyang, J.; Wen, M.; Zeng, K.; Chen, W.; Zhang, L.; Liu, Y. A NIR-II light responsive hydrogel based on 2D engineered tungsten nitride nanosheets for multimode chemo/photothermal therapy. Chem. Commun. 2019. $55,9471$.

[224] Rees, P.; Wills, J.W.; Brown, M.R.; Barnes, C.M.; Summers, H.D. The origin of heterogeneous nanoparticle uptake by cells. Nat Commun. 2019. 10(1), 2341. [225] Lesniak, A.; Fenaroli, F.; Monopoli, M.P.; Åberg, C.; Dawson, K.A.; Salvati, A. Effects of the presence or absence of a protein corona on silica nanoparticle uptake and impact on cells. ACS Nano. 2012. 6(7), 5845-57.

[226] Panwar, N.; Soehartono, A.M.; Chan, K. K.; Zeng, S.; Xu, G.; Qu, J.; Coquet, P.; Yong, K.; Chen, X. Nanocarbons for Biology and Medicine: Sensing, Imaging, and Drug Delivery. Chem Rev. 2019. 119(16), 9559-9656.

[227] Huang, K. J.; Lee, C. Y.; Lin, Y. C.; Lin, C. Y.; Perevedentseva, E.; Hung, S. F.; Cheng, C. L. Phagocytosis and immune response studies of MacrophageNanodiamond Interactions in vitro and in vivo. J Biophotonics. 2017. 10(10), 13151326.

[228] Raja, I. S ; Song, S. J. ; Kang, M. S. ; Lee, Y. B. ;, Kim, B. ; Hong, S. W. ; Jeong, S. J. ; Lee, J. C. ; Han, D. W. Toxicity of Zero- and One-Dimensional Carbon Nanomaterials. Nanomaterials (Basel). 2019. 9(9), 1214. 
[229] Rydman, E. M.; Ilves, M.; Koivisto, A. J.; Kinaret, P. A. S.; Fortino, V.; Savinko, T. S.; Lehto, M. T.; Pulkkinen, V.; Vippola, M.; Hämeri, K. J.; Matikainen, S.; Wolff, H.; Savolainen, K. M.; Greco, D.; Alenius, H. Inhalation of rod-like carbon nanotubes causes unconventional allergic airway inflammation. Part Fibre Toxicol. 2014. 11, 48.

[230] Ali-Boucetta, H.; Nunes, A.; Sainz, R.; Herrero, M. A.; Tian, B.; Prato, M.; Bianco, A.; Kostarelos, K. Asbestos-like pathogenicity of long carbon nanotubes alleviated by chemical functionalization. Angew Chem Int Ed Engl. 2013. 52(8), 2274-8.

[231] Boyles, M. S. P.; Young, L.; Brown, D. M.; MacCalman, L.; Cowie, H.; Moisala, A.; Smail, F.; Smith, P.J.W.; Proudfoot, L.; Windle, A. H.; Stone, V.

Multi-walled carbon nanotube induced frustrated phagocytosis, cytotoxicity and proinflammatory conditions in macrophages are length dependent and greater than that of asbestos. Toxicol In Vitro. 2015. 29(7), 1513-28.

[232] Schinwald, A.; Murphy, F.A.; Jones, A.; MacNee, W.; Donaldson, K.

6

Graphene-based nanoplatelets: a new risk to the respiratory system as a consequence of their unusual aerodynamic properties. ACS Nano. 2012. 6(1), 736-46.

[233] Li, Y.; Yuan, H.; von dem Bussche, A.; Creighton, M.; Hurt, R. H.; Kane, A. B.; Gao, H. Graphene microsheets enter cells through spontaneous membrane penetration at edge asperities and corner sites. Proc Natl Acad Sci U S A. 2013. $110(30), 12295-300$.

[234] Bussy, C.; Ali-Boucetta, H.; Kostarelos, K. Safety considerations for graphene: lessons learnt from carbon nanotubes. Acc Chem Res. 2013. 46(3), 692-701.

[235] Franqui, L.S.; de Farias, M.A.; Portugal, R.; Costa, C.; Domingues, R.R.; Souza Filho, A.S.; Coluci, V.; Leme, A.F.P.; Martinez, D. Interaction of graphene oxide with cell culture medium: evaluating the fetal bovine serum protein corona formation towards in vitro nanotoxicity assessment and nanobiointeractions. Mater. Sci. Eng. C Mater. Biol. Appl. 2019. 100, 363-377.

[236] Kusaka, T.; Nakayama, M.; Nakamura, K.; Ishimiya, M.; Furusawa, E.; Ogasawara, K. Effect of silica particle size on macrophage inflammatory responses. PLoS One. 2014. 9(3), 92634. 
1
2
3 
2

Tab3e 1. Dose and time-dependent effects of different $\mathrm{MoS}_{2}$ materials on macrophages

\begin{tabular}{|c|c|c|c|c|c|c|c|c|}
\hline Compound & $\begin{array}{l}\text { Average } \\
\text { Size }\end{array}$ & Cell type & Cytokines & ROS & Duration & Dose & Other effects & Ref \\
\hline $\begin{array}{l}\mathrm{MoS}_{2} \text { (aggregated, } \\
\text { 2D lithiation or 2D } \\
\text { pluronic dispersed) }\end{array}$ & - & THP-1 & $\begin{array}{c}\text { Produced } \\
\text { TNF- } \alpha \text { and IL- } \\
1 \beta\end{array}$ & - & $24 \mathrm{~h}$ & $\begin{array}{c}6.25-50 \\
\mu g / m L\end{array}$ & - & [152] \\
\hline $\begin{array}{c}\mathrm{MoS}_{2} @ \\
\text { PEG ET-loaded }\end{array}$ & $\begin{array}{c}200-300 \\
\mathrm{~nm}\end{array}$ & RAW 264.7 & $\begin{array}{l}\text { Inhibited TNF- } \\
\alpha \text {, promoted } \\
\text { IL-10 }\end{array}$ & - & $2 \mathrm{~h}$ & $\begin{array}{l}0-150 \\
\mu \mathrm{g} / \mathrm{mL}\end{array}$ & $\begin{array}{c}\text { Inhibited iNOS, } \\
\text { CD86; } \\
\text { promoted Arg1, } \\
\text { CD206 }\end{array}$ & [154] \\
\hline $\mathrm{MoS}_{2}$ & $120 \mathrm{~nm}$ & $\begin{array}{l}\text { THP-1-derived } \\
\text { macrophages }\end{array}$ & 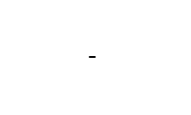 & - & $4,24,72 \mathrm{~h}$ & $\begin{array}{c}100 \\
\mu \mathrm{g} / \mathrm{mL}\end{array}$ & $\begin{array}{c}\text { Increase in } \\
\text { intracellular } \\
\text { lipids }\end{array}$ & [155] \\
\hline $\mathrm{MoS}_{2}$ & $150 \mathrm{~nm}$ & $\begin{array}{l}\text { Primary human } \\
\text { macrophages }^{a}\end{array}$ & $\begin{array}{l}\text { TNF- } \alpha \text { and IL-6 } \\
\text { (M1) }\end{array}$ & $\begin{array}{l}\text { Produced ROS } \\
\text { (M1) }\end{array}$ & $24 \mathrm{~h}$ & $\begin{array}{c}5-50 \\
\mu \mathrm{g} / \mathrm{mL}\end{array}$ & $\begin{array}{l}\text { Decreased } \\
\text { CD80 (M1) }\end{array}$ & [55] \\
\hline $\mathrm{MoS}_{2}$ and $\mathrm{f}-\mathrm{MoS}_{2}$ & - & RAW 264.7 & $\begin{array}{l}\text { No significant } \\
\text { TNF- } \alpha \text { and IL-6 } \\
\text { production }\end{array}$ & - & $24 \mathrm{~h}$ & $\begin{array}{c}1-75 \\
\mu \mathrm{g} / \mathrm{mL}\end{array}$ & $\begin{array}{l}\text { No immune } \\
\text { activation }\end{array}$ & [156] \\
\hline
\end{tabular}

a) PrAmary human macrophages were differentiated into M1 and M2 phenotypes.

5

6

7

8

9

10

11

12

13

14

15

16

17

18

19

20

21

22

23

24

25 


\section{1}

Table 2. Dose and time-dependent effects of different $\mathrm{MnO}_{2}$ materials on macrophages

\begin{tabular}{|c|c|c|c|c|c|c|c|c|}
\hline Compound & $\begin{array}{l}\text { Average } \\
\text { Size }\end{array}$ & Cell type & Cytokines & ROS & Duration & Dose & Other effects & Ref \\
\hline PEG-MnO 2 NPs & $15 \mathrm{~nm}$ & $\begin{array}{l}\text { Primary rat } \\
\text { macrophages }\end{array}$ & $\begin{array}{l}\text { Decreased } \\
\text { TNF- } \alpha\end{array}$ & - & $24 \mathrm{~h}$ & $\begin{array}{l}5-100 \\
\mu \mathrm{g} / \mathrm{mL}\end{array}$ & - & [164] \\
\hline $\mathrm{MnO}_{2}$ nanoparticles & - & $\begin{array}{l}\text { guinea pig } \\
\text { alveolar } \\
\text { macrophages }\end{array}$ & - & - & $1-6 \mathrm{~h}$ & $\begin{array}{c}2.5 \\
\mathrm{mg} / \mathrm{mL}\end{array}$ & $\begin{array}{l}\text { Increased } \\
\text { neutrophil } \\
\text { migration }\end{array}$ & [165] \\
\hline $\begin{array}{l}\text { Hyaluronic acid-coated, } \\
\text { mannan-conjugated } \\
\mathrm{MnO}_{2} \\
\text { particles }\end{array}$ & $203 \mathrm{~nm}$ & RAW 264.7 & $\begin{array}{l}\text { Increased IL- } \\
\text { 12, decreased } \\
\text { IL-10 }\end{array}$ & - & $24 \mathrm{~h}$ & $0.5-5 \mu \mathrm{M}$ & $\begin{array}{c}\text { Decreased HIF- } 1 \alpha \\
\text { VEGF. } \\
\text { Pro-M1 }\end{array}$ & [166] \\
\hline 3 & & & & & & & & \\
\hline 4 & & & & & & & & \\
\hline 5 & & & & & & & & \\
\hline 6 & & & & & & & & \\
\hline 7 & & & & & & & & \\
\hline 8 & & & & & & & & \\
\hline 9 & & & & & & & & \\
\hline 10 & & & & & & & & \\
\hline 11 & & & & & & & & \\
\hline 12 & & & & & & & & \\
\hline 13 & & & & & & & & \\
\hline 14 & & & & & & & & \\
\hline 15 & & & & & & & & \\
\hline 16 & & & & & & & & \\
\hline 17 & & & & & & & & \\
\hline 18 & & & & & & & & \\
\hline 19 & & & & & & & & \\
\hline 20 & & & & & & & & \\
\hline 21 & & & & & & & & \\
\hline 22 & & & & & & & & \\
\hline 23 & & & & & & & & \\
\hline 24 & & & & & & & & \\
\hline 25 & & & & & & & & \\
\hline 26 & & & & & & & & \\
\hline 27 & & & & & & & & \\
\hline 28 & & & & & & & & \\
\hline
\end{tabular}


1

Table 3. Dose and time-dependent effects of different boron materials on macrophages

\begin{tabular}{|c|c|c|c|c|c|c|c|c|}
\hline Compound & $\begin{array}{l}\text { Average } \\
\text { size }^{\text {a) }}\end{array}$ & Cell type & Cytokines & ROS & Duration & Dose & Other effects & Ref \\
\hline $\begin{array}{l}\text { Boron nitride } \\
\text { nanotubes }\end{array}$ & $\begin{array}{l}0.1-0.3 \\
\mathrm{~mm}\end{array}$ & $\begin{array}{l}\text { THP-1-derived } \\
\text { macrophages }\end{array}$ & $\begin{array}{c}\text { Increased IL-1 } \beta, \text { II- } \\
18\end{array}$ & - & $24 \mathrm{~h}$ & $\begin{array}{l}0-100 \\
\mu \mathrm{g} / \mathrm{mL}\end{array}$ & $\begin{array}{l}\text { Increased } \\
\text { cathepsin B, } \\
\text { caspase } 1\end{array}$ & [186] \\
\hline Boron & - & $\begin{array}{l}\text { Mouse } \\
\text { macrophages (in } \\
\text { vivo) }\end{array}$ & $\begin{array}{c}\text { Increased TNF- } \alpha, \text { IL- } \\
\text { 6, IL-1 } 1 \beta, \text { NO. }\end{array}$ & - & $10 d$ & $\begin{array}{c}4.6 \\
\mathrm{mg} / \mathrm{kg}\end{array}$ & Increased iNOS & [187] \\
\hline $\begin{array}{l}\text { Pectin-coated } \\
\text { boron nitride } \\
\text { nanotubes }\end{array}$ & $2.0 \mu \mathrm{m}$ & RAW 264.7 & $\begin{array}{c}\text { Did not release IL-6, } \\
\text { IL-10, TNF- } \alpha . \\
\text { Decreased IL-1 }\end{array}$ & $\begin{array}{l}\text { No } \\
\text { oxidative } \\
\text { stress }\end{array}$ & $24 \mathrm{~h}$ & $\begin{array}{c}0-50 \\
\mu \mathrm{g} / \mathrm{mL}\end{array}$ & - & [188] \\
\hline
\end{tabular}

a) Length

4

5

6

7

8

9

10

11

12

13

14

15

16

17

18

19

20

21

22

23

24

25

26

27

28

29 


\section{1}

Table 4. Dose and time-dependent effects of different black phosphorus materials on macrophages

\begin{tabular}{|c|c|c|c|c|c|c|c|c|}
\hline Compound & Average size & Cell type & Cytokines & ROS & Duration & Dose & Other effects & Ref \\
\hline $\begin{array}{l}\text { BP quantum dots } \\
\text { with titanium } \\
\text { sulphonate }\end{array}$ & $3.3 \mathrm{~nm}$ & $\begin{array}{l}\text { J774A.1 and } \\
\text { RAW264.7 }\end{array}$ & $\begin{array}{l}\text { Increased TNF- } \\
\alpha \text { in BP alone, } \\
\text { return to } \\
\text { normality with } \\
\text { titanium } \\
\text { sulphonate }\end{array}$ & $\begin{array}{l}\text { Low } \\
\text { production }\end{array}$ & $6,24 \mathrm{~h}$ & $\begin{array}{c}10 \\
\mu \mathrm{g} / \mathrm{mL}\end{array}$ & ATP decline & [201] \\
\hline $\begin{array}{l}\text { BPquantum dots } \\
\text { and nanosheets }\end{array}$ & $\begin{array}{l}\text { Quantum dots } \\
\text { (5 nm); } \\
\text { nanosheets } \\
(300 \mathrm{~nm})\end{array}$ & $\begin{array}{l}\text { THP-1-derived } \\
\text { macrophages } \\
\text { PBMCs }\end{array}$ & $\begin{array}{l}\text { Increased IL-1 } \beta \text {, } \\
\text { IL-6, IL-8, IFN- } \lambda \\
\text { Increased IL-1 } \\
\text { IL-6, IL-8, IL-9, } \\
\text { IL-10 }\end{array}$ & - & $6,24 \mathrm{~h}$ & $\begin{array}{c}0-50 \\
\mu \mathrm{g} / \mathrm{mL}\end{array}$ & $\begin{array}{l}\text { Corona } \\
\text { influences } \\
\text { uptake and } \\
\text { toxicity }\end{array}$ & [202] \\
\hline BP-corona complex & $207 \mathrm{~nm}$ & RAW 264.7 & $\begin{array}{c}\text { Increased TNF- } \\
\alpha, \mathrm{IL}-12 \\
\end{array}$ & - & $24 \mathrm{~h}$ & $\begin{array}{c}15 \\
\mu \mathrm{g} / \mathrm{mL} \\
\end{array}$ & $\begin{array}{c}\text { Increased } \\
\text { iNOS, CD16 } \\
\end{array}$ & [203] \\
\hline 3 & & & & & & & & \\
\hline 4 & & & & & & & & \\
\hline 5 & & & & & & & & \\
\hline 6 & & & & & & & & \\
\hline 7 & & & & & & & & \\
\hline 8 & & & & & & & & \\
\hline 9 & & & & & & & & \\
\hline 10 & & & & & & & & \\
\hline 11 & & & & & & & & \\
\hline 12 & & & & & & & & \\
\hline 13 & & & & & & & & \\
\hline 14 & & & & & & & & \\
\hline 15 & & & & & & & & \\
\hline 16 & & & & & & & & \\
\hline 17 & & & & & & & & \\
\hline 18 & & & & & & & & \\
\hline 19 & & & & & & & & \\
\hline 20 & & & & & & & & \\
\hline 21 & & & & & & & & \\
\hline 22 & & & & & & & & \\
\hline 23 & & & & & & & & \\
\hline 24 & & & & & & & & \\
\hline 25 & & & & & & & & \\
\hline 26 & & & & & & & & \\
\hline
\end{tabular}


1

Table 5. Dose and time-dependent effects of different tungsten materials on macrophages

\begin{tabular}{|c|c|c|c|c|c|c|c|c|}
\hline Compound & Average size & Cell type & Cytokines & ROS & Duration & Dose & Other effects & Ref \\
\hline WC-Co & $\begin{array}{c}95.53 \mathrm{~nm} \text { and } \\
39.00 \mu \mathrm{m}\end{array}$ & $\begin{array}{c}\text { Rat lung } \\
\text { macrophages (In } \\
\text { vivo) }\end{array}$ & - & Induced ROS & 7-21 days & $\begin{array}{c}1 \% \\
\text { solution } \\
\text { in saline }\end{array}$ & Pro-apoptotic & [215] \\
\hline WC-Co & $98 \mathrm{~nm}$ & $\begin{array}{c}\text { THP-1 Beas-2B co- } \\
\text { culture }\end{array}$ & $\begin{array}{c}\text { Increased IL- } 1 \beta \text {, } \\
\text { IL-12, decreased } \\
\text { TNF- } \alpha\end{array}$ & - & $2-48 \mathrm{~h}$ & $\begin{array}{c}1-1,000 \\
\mu \mathrm{g} / \mathrm{mL}\end{array}$ & $\begin{array}{c}\text { Increased CD40, } \\
\text { pro-M1 }\end{array}$ & [217] \\
\hline $\begin{array}{c}\text { Sodium } \\
\text { Polyoxo-tungstate } \\
\text { (POM-1) }\end{array}$ & - & $\begin{array}{c}\text { Primary mouse } \\
\text { macrophages }\end{array}$ & $\begin{array}{l}\text { Decreased TNF- } \alpha \text {, } \\
\text { IL-1 } \beta\end{array}$ & - & $\begin{array}{c}30 \mathrm{~min} \text { to } \\
24 \mathrm{~h}\end{array}$ & $100 \mu \mathrm{M}$ & $\begin{array}{c}\text { Blocks } \\
\text { cytoplasmic } \\
\mathrm{Ca}^{2+} \text { release }\end{array}$ & [218] \\
\hline $\begin{array}{c}\mathrm{CaWO}_{4}, \mathrm{SrWO}_{4} \\
\mathrm{BaWO}_{4}, \mathrm{Na}_{2} \mathrm{WO}_{4} \\
\text { in wire \& sphere } \\
\text { form }\end{array}$ & $\begin{array}{c}\mathrm{BaWO}_{4} \\
\text { spheres (1 } \\
\mu \mathrm{m}) ; \text { other } \\
\text { spheres } 400 \\
\text { nm. All } \\
\text { nanowires } \\
\text { were } 100 \mathrm{~nm}\end{array}$ & RAW 264.7 & $\begin{array}{l}\text { No production of } \\
\text { IL-6, IL-8 or TNF- } \alpha \text {. }\end{array}$ & $\begin{array}{c}\text { Tungstate } \\
\text { nanowires } \\
\text { produce ROS }\end{array}$ & $24 \mathrm{~h}$ & $\begin{array}{c}50 \\
\mu \mathrm{g} / \mathrm{mL}\end{array}$ & $\begin{array}{l}\text { No DNA } \\
\text { damage }\end{array}$ & [219] \\
\hline $\mathrm{Na}_{2} \mathrm{WO}_{4}$ & - & THP-1 & $\begin{array}{l}\text { Induced IL-10, } \\
\text { TNF- } \alpha \text {, IL-6 }\end{array}$ & - & $72 \mathrm{~h}$ & $\begin{array}{c}0.01-10 \\
\mathrm{mM}\end{array}$ & $\begin{array}{l}\text { Altered cell } \\
\text { cycle } \\
\text { progression }\end{array}$ & [220] \\
\hline WC-Co & $100 \mathrm{~nm}$ & $\begin{array}{c}\text { Rat alveolar } \\
\text { macrophages (in } \\
\text { vivo) }\end{array}$ & $\begin{array}{l}\text { No production of } \\
\text { IL-6 }\end{array}$ & - & $24 \mathrm{~h}$ & $\begin{array}{l}0-500 \mu g \\
\text { per rat }\end{array}$ & $\begin{array}{l}\text { No pulmonary } \\
\text { inflammation }\end{array}$ & [221] \\
\hline
\end{tabular}




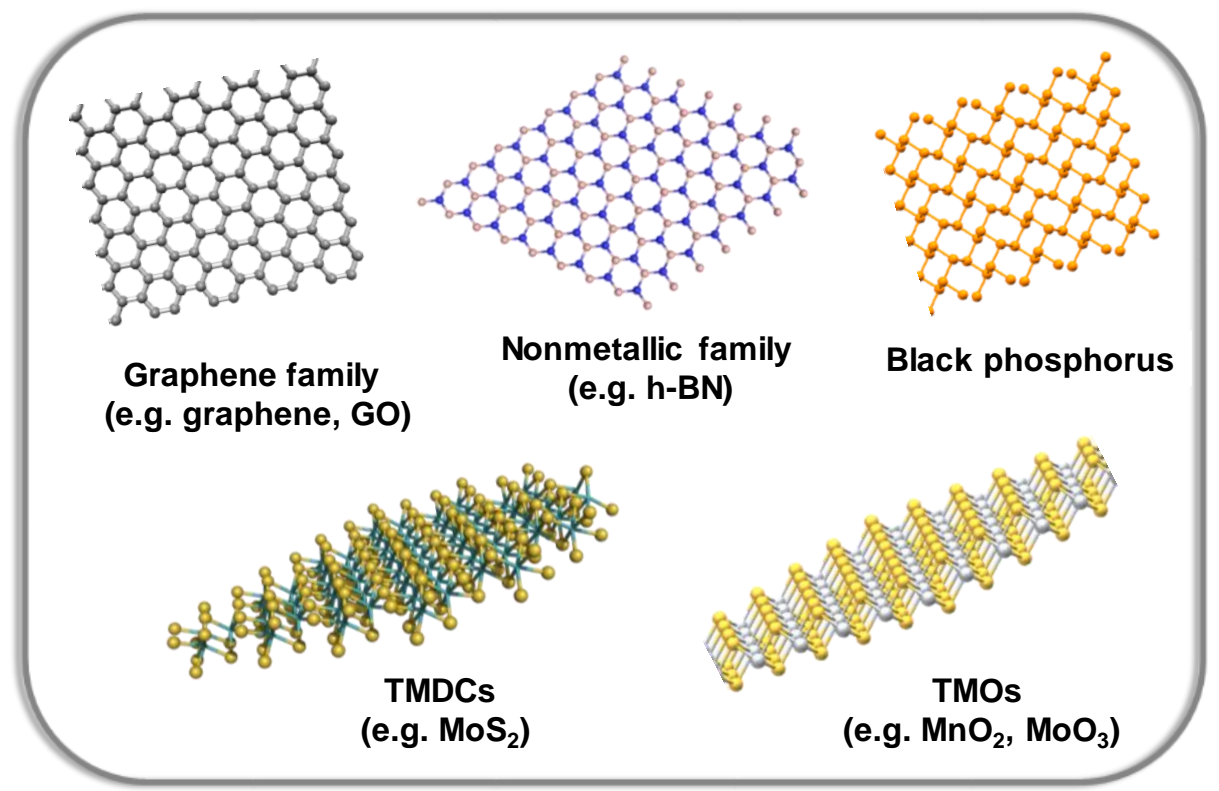

3

Figure 1.

4

5

6

7

8

9

10

11 


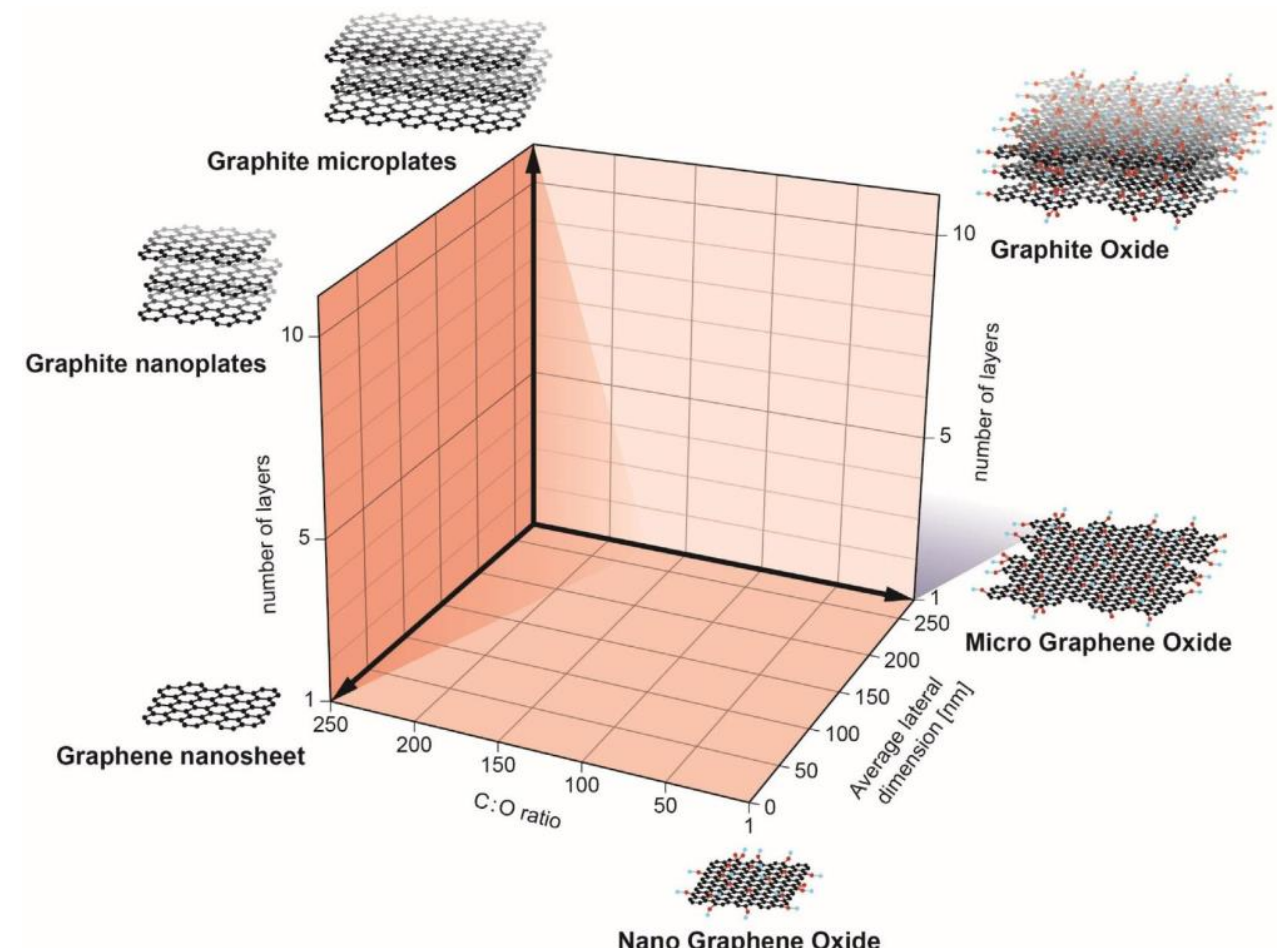

Nano Graphene Oxide

2

$3 \quad$ Figure 2.

4

5

6

7

8

9

10

11

12

13 


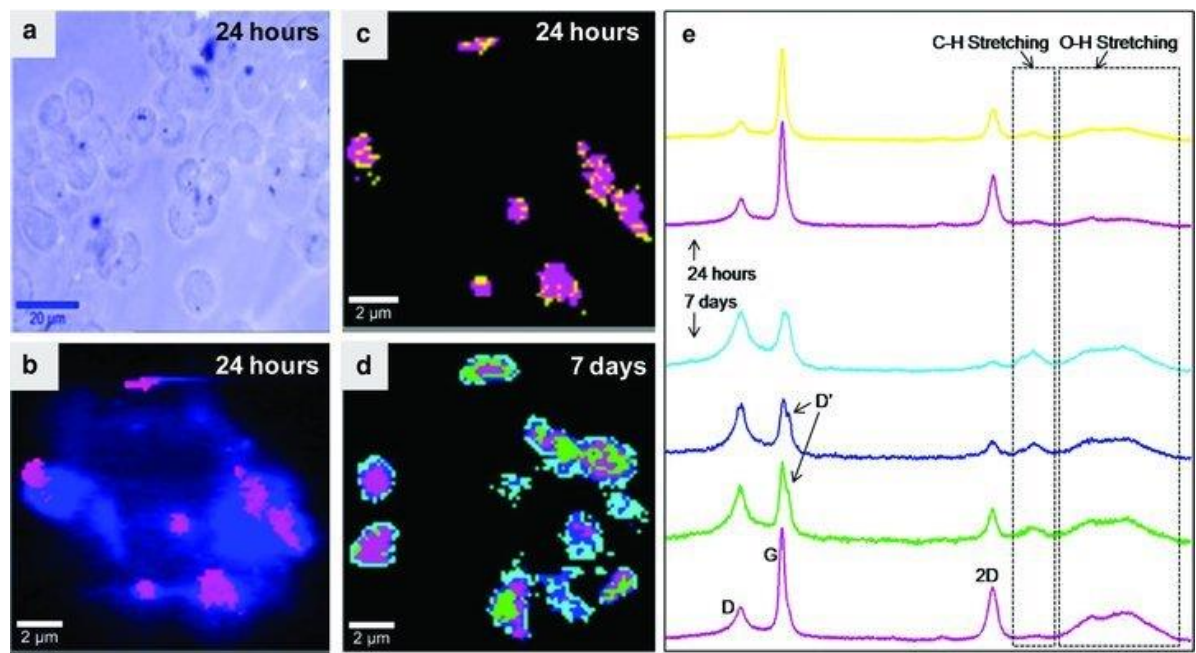

2 Figure 3.

3

4

5

6

7

8

9

10

11

12

13

14

15

16

17 


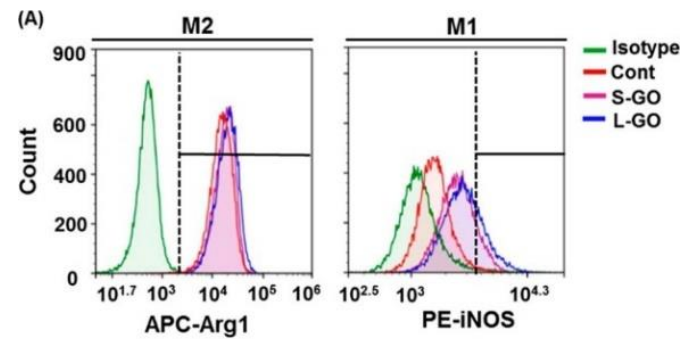

1
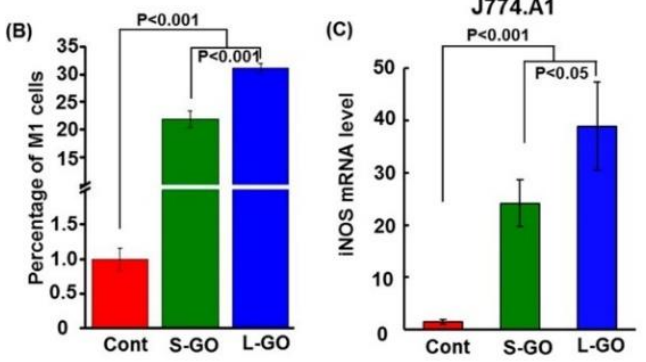

$2 \quad$ Figure 4.

3

4

5

6

7

8

9

10

11

12 
a
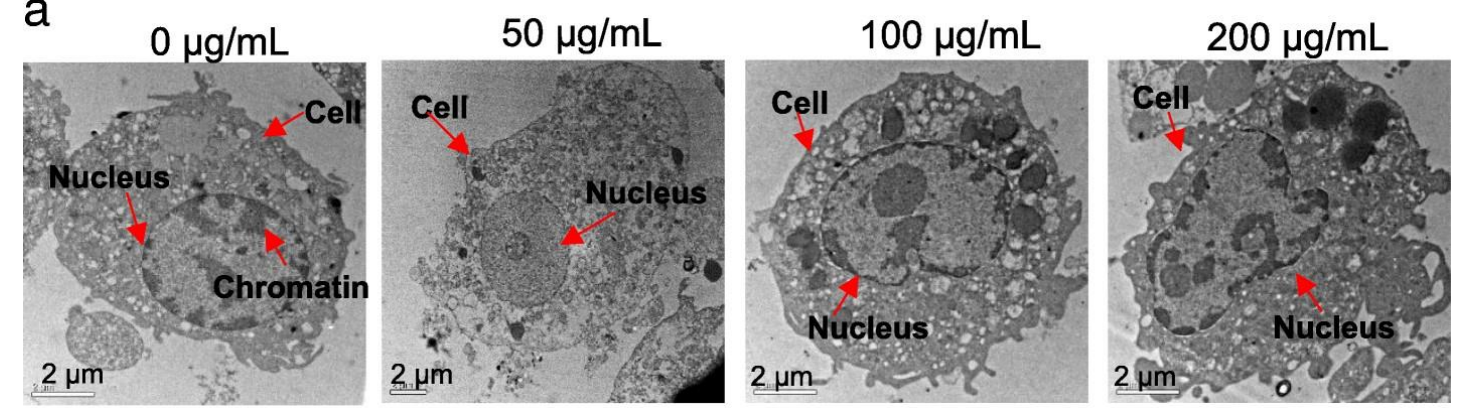

b
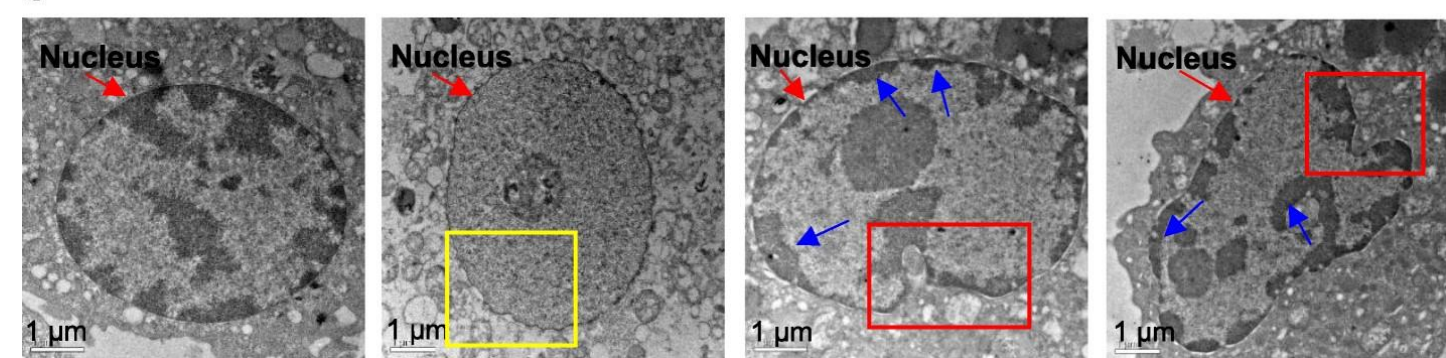

\section{$2 \quad$ Figure 5.}

3

4

5

6

7

8

9

10 

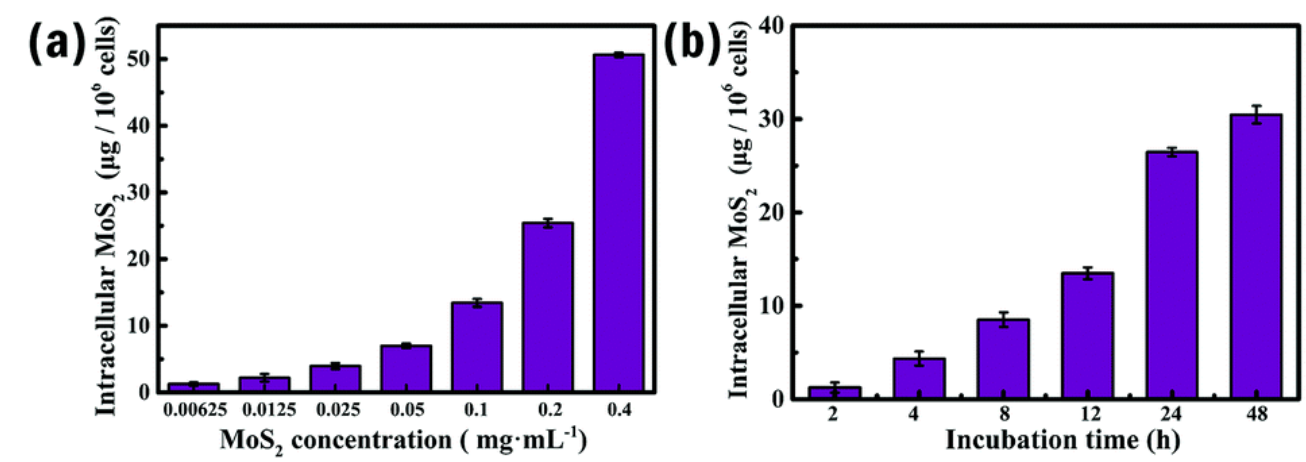

(c)

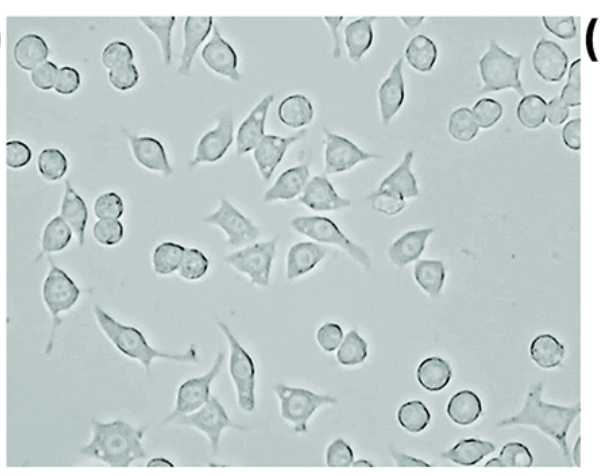

(d)

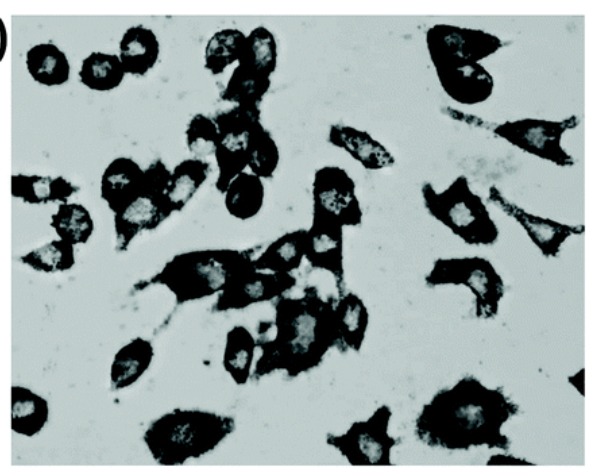

2

Figure 6.

4

5

6

7

8

9

10 

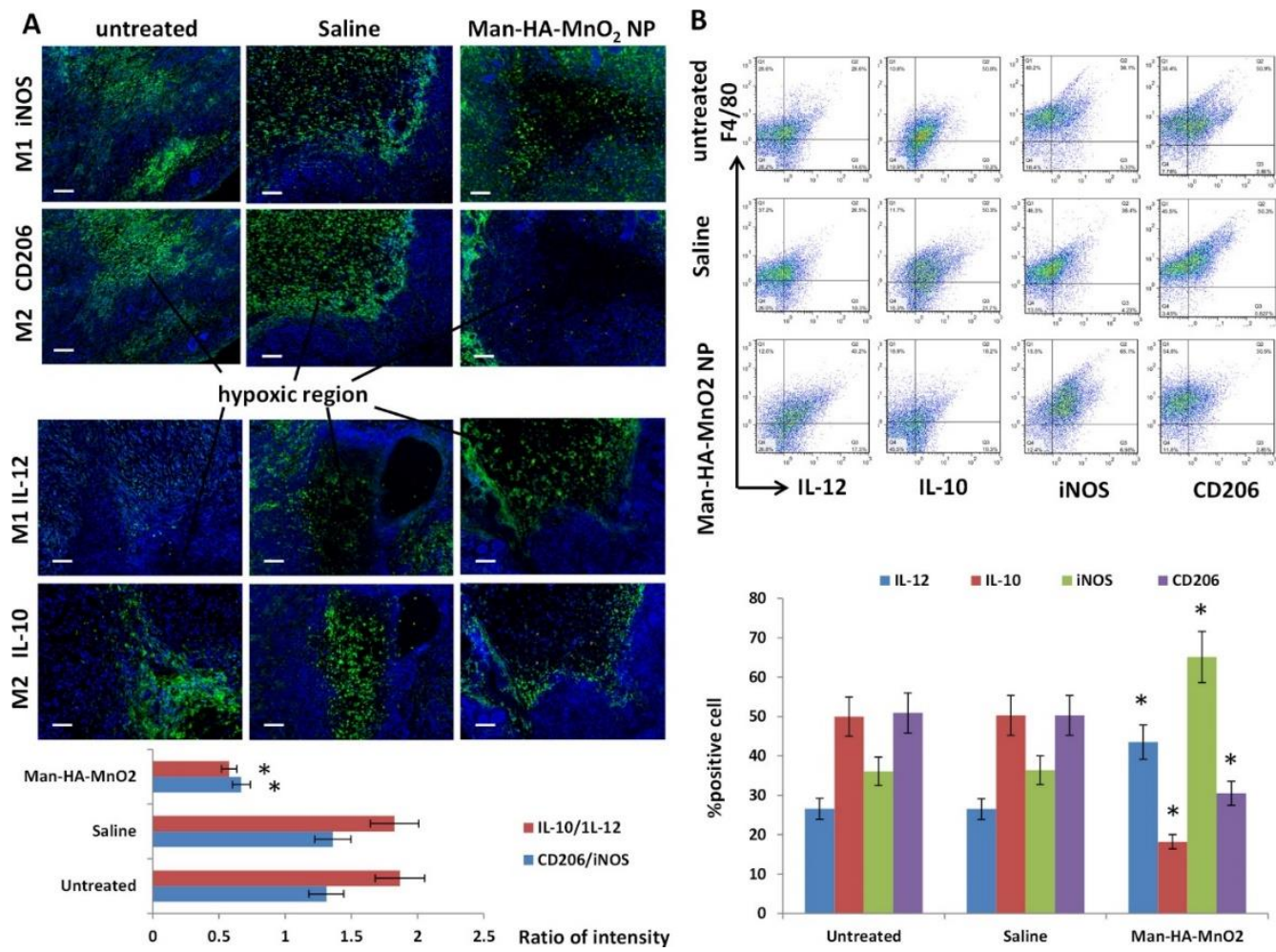

2

$3 \quad$ Figure 7.

4

5

6

7

8

9

10

11

12 

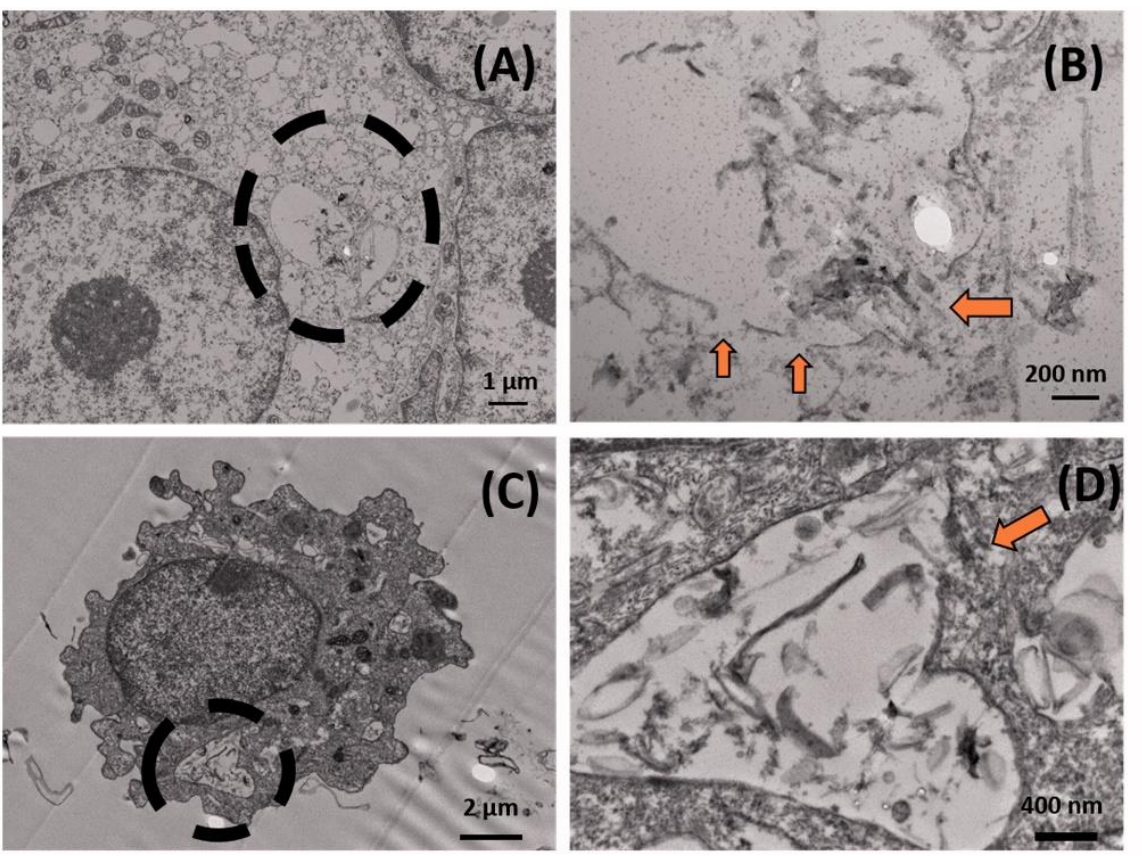

2

3

Figure 8.

4

5

6

7

8

9

4
(E)

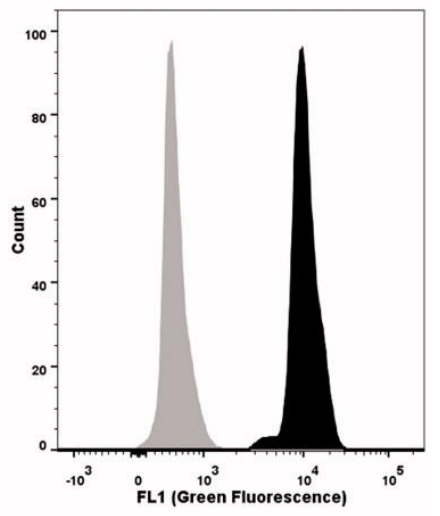

Control $(0 \mu \mathrm{g} / \mathrm{ml})$

BNNT-M $(25 \mu \mathrm{g} / \mathrm{ml})$ 

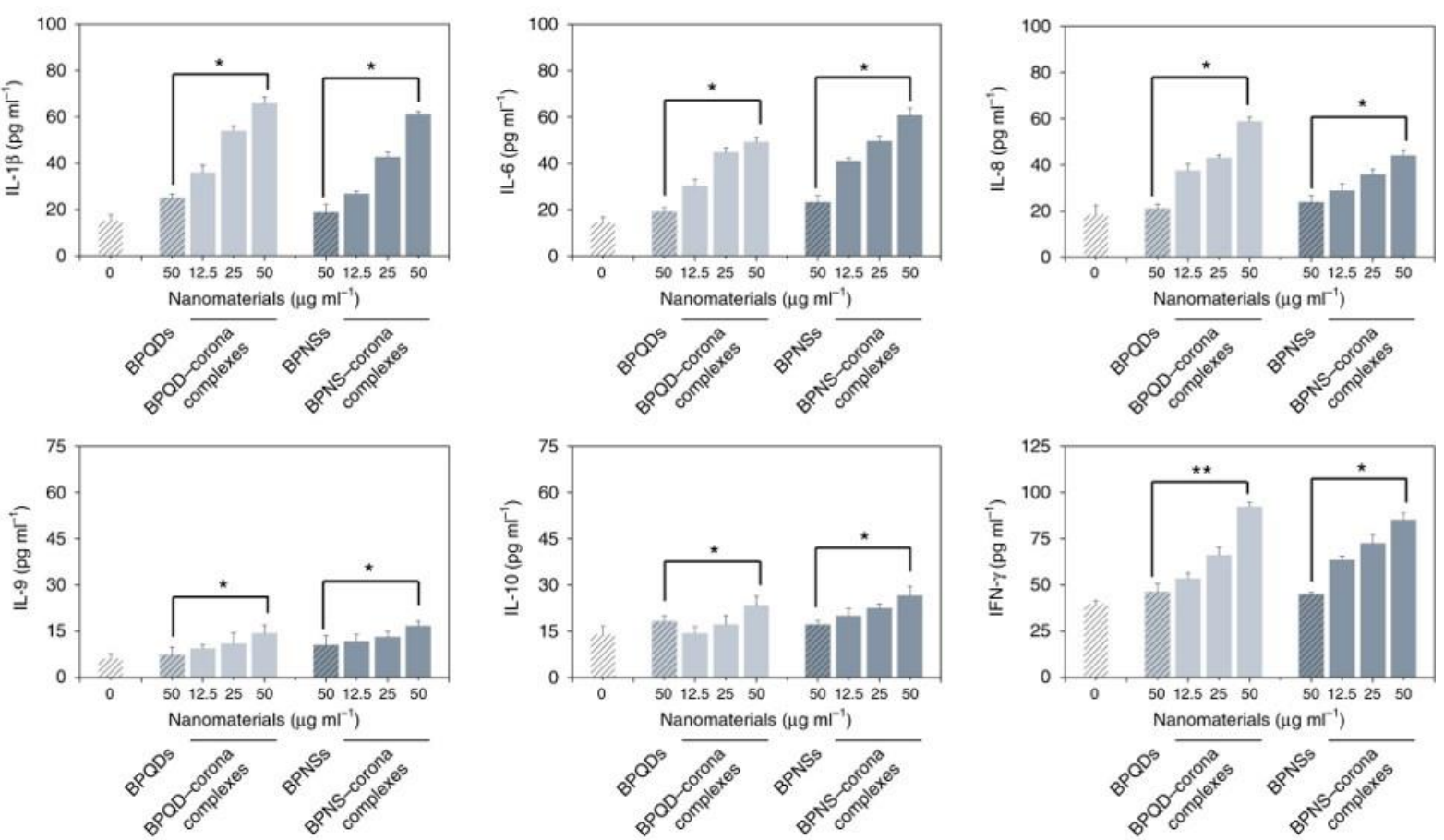

\section{$2 \quad$ Figure 9.}

3

4

5

6

7

8

9

10

11

12

13

14 

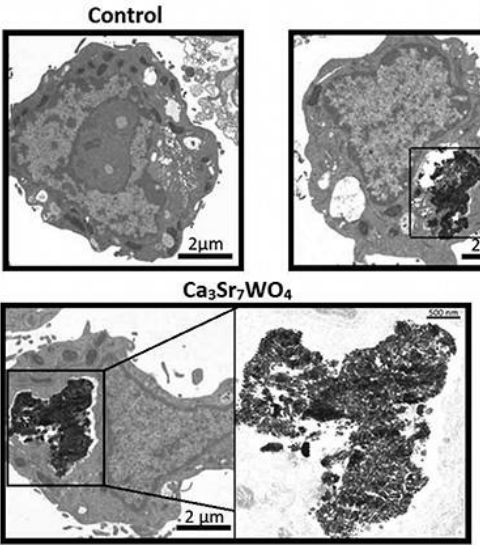

$\mathrm{CaWO}_{4}$

$\mathrm{SrWO}_{4}$
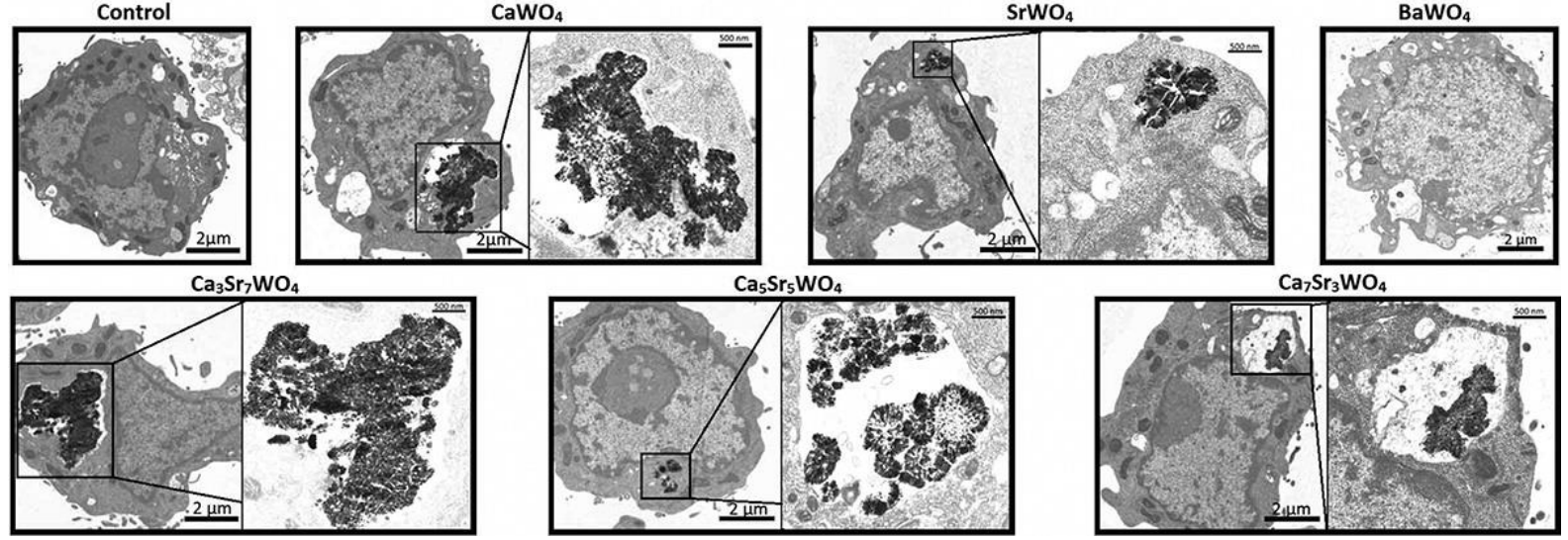

2

3

Figure 10.

4

5

6

7

8

9

10

11

12

13

14

15

16

17

18

19

20

21 


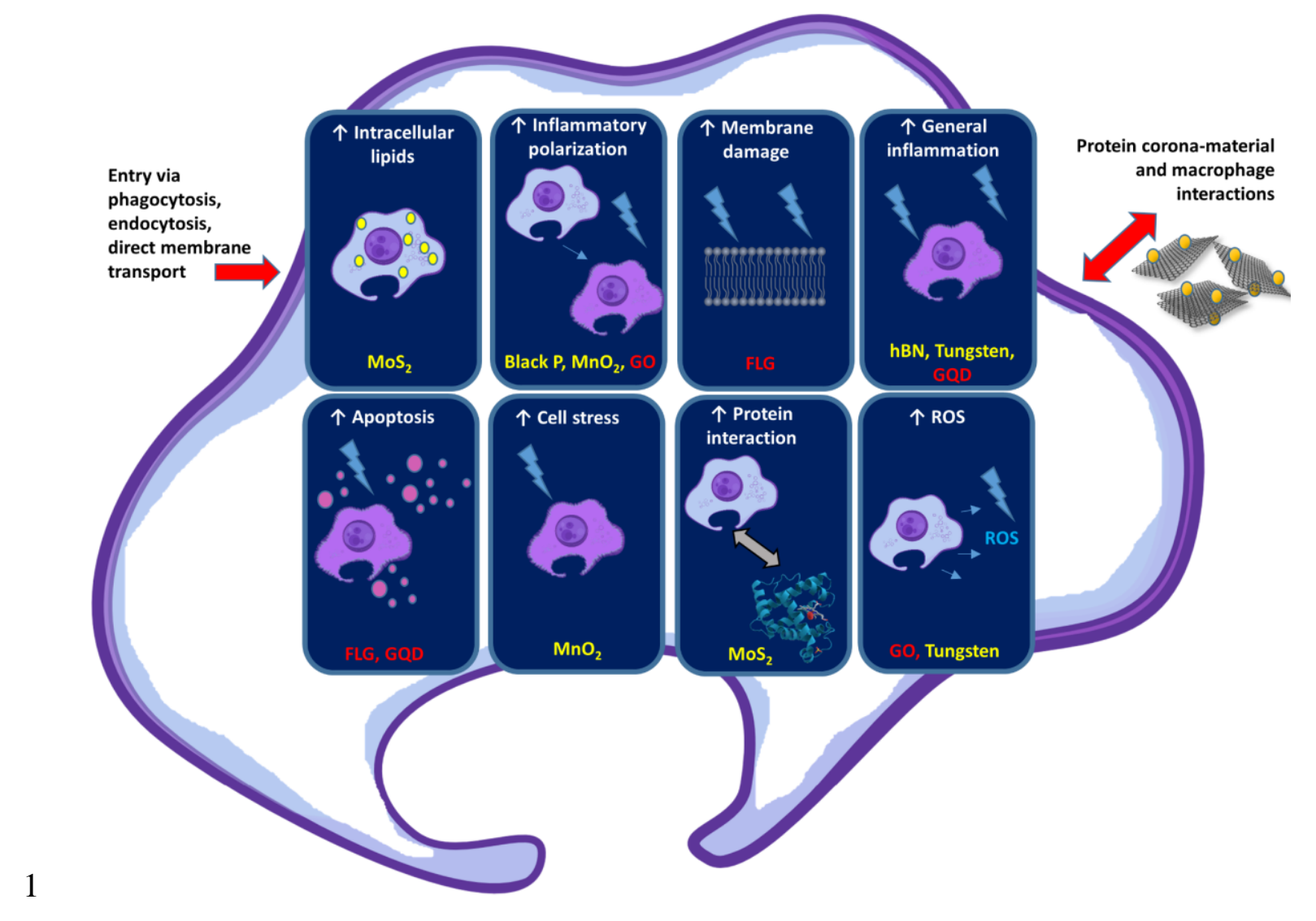

$2 \quad$ Figure 11.

3

4

5

6

7

8

9

10

11

12

13

14 


\section{$1 \quad$ Figure captions (list)}

2

3 Figure 1. Different types of 2D materials described in this review.

4

5 Figure 2. Categorization of graphene-based materials based on three parameters; C/O 6 ratio, average lateral size and number of layers. Reprinted with permission. ${ }^{[47]}$ Copyright 7 2014, John Wiley \& Sons, Inc.

8

9 Figure 3. (a) Bright field and (b) Raman images of graphene-RAW 264.7 after $24 \mathrm{~h}$ of 10 incubation. Secondary cluster maps of graphene aggregates localized within the cells at $1124 \mathrm{~h}(\mathrm{c})$ and $7 \mathrm{~d}(\mathrm{~d})$, are represented by false color codes. (e) Averaged spectra of graphene 12 from the sub-cluster regions. Dotted boxes represent the C-H stretching (2800-3050/cm) 13 from cells and $\mathrm{O}-\mathrm{H}$ stretching $(3100-3700 / \mathrm{cm})$ from PBS solution. Reprinted with 14 permission. ${ }^{[64]}$ Copyright 2013, John Wiley \& Sons, Inc.

16 Figure 4. GO induced macrophage polarization to M1 subtype in a size-dependent 17 manner. (A) Representative histograms showing the numbers of M2 (Arg1 $1^{+}$and M1 18 (iNOS $^{+}$) cells. J774.A1 cells were treated with small GO (S-GO) or large GO (L-GO) at $1920 \mu \mathrm{g} / \mathrm{mL}$ for $24 \mathrm{~h}$, followed by FACS analysis. (B) Percentages of $\operatorname{iNOS}^{+}$cells $(\mathrm{n}=5)$.

20 (C) Relative iNOS level in J774.A1 cells upon exposure to S-GO or L-GO at $20 \mu \mathrm{g} / \mathrm{mL}$

21 for $24 \mathrm{~h}$. HPRT1 was used as control for normalization. Reprinted with permission. ${ }^{\text {[94] }}$ 22 Copyright 2015, American Chemistry Society.

24 Figure 5. TEM images of NR8383 nuclear morphology after exposure to AG-QDs (0, 2550,100 , and $200 \mu \mathrm{g} / \mathrm{mL}$ ) for $24 \mathrm{~h}$. The images in panel (b) are enlarged from panel (a). 
1 In panel (b), the yellow box indicates the shrinking of the inner nuclear envelope after

2 AG-QDs $(50 \mu \mathrm{g} / \mathrm{mL})$ exposure. The red boxes indicate the malformation of nuclear

3 morphology after AG-QDs (100 and $200 \mu \mathrm{g} / \mathrm{mL})$ exposure. The blue arrows indicate the

4 chromatin condensation (electron-dense, black structure along nuclear membrane)

5 within the nuclei. Reprinted with permission. ${ }^{[133]}$ Copyright 2018, BioMed Central

6 Ltd, Springer Nature.

7

8 Figure 6. Phagocytosis of $\mathrm{MoS}_{2}$ by macrophages. Quantitative analysis of the effect of

9 (a) $\mathrm{MoS}_{2}$ concentration and (b) incubation time on loading capacity; (c) and (d)

10 microphotographs of macrophages before and after BSA-MoS 2 loading, respectively $(\mathrm{t}=$

$1124 \mathrm{~h}, \mathrm{BSA}-\mathrm{MoS}_{2}$ is $0.2 \mathrm{mg} / \mathrm{mL}$ ). Reprinted with permission. ${ }^{[152]}$ Copyright 2019, The

12 Royal Society of Chemistry.

14 Figure 7. Man-HA- $\mathrm{MnO}_{2}$ skews TAMs M2 phenotype toward M1 phenotype. (A)

15 Representative immunofluorescence images of tumour sections stained with M1 and

16 M2 macrophage marker (green) after Man-HA- $\mathrm{MnO}_{2}$ administration. The orange dots

17 are Man-HA-MnO 2 . Magnification 100 ×; scale bar $100 \mu \mathrm{m}$. (B) Flow cytometric

18 analysis of phenotype of macrophages in tumours after administration of Man-HA-

$19 \mathrm{MnO}_{2}(\mathrm{n}=5 /$ group$)$. Error bars are standard error of the mean. $* \mathrm{p}<0.05$ compared to

20 untreated control. Reprinted with permission. ${ }^{[166]}$ Copyright 2016, American Chemical

21 Society Publications.

23 Figure 8. Ultrastructural evidence confirming uptake and lysosomal rupture in vitro and

24 in vivo. (A) TEM image of a differentiated THP-1 macrophage exposed to $25 \mathrm{mg} / \mathrm{mL}$

$25\left(7.79 \mathrm{mg} / \mathrm{cm}^{2}\right)$ of BNNT-M for $6 \mathrm{~h}$ (BNNT-M: mixture of BNNT, impurities of boron 
1 and $\mathrm{hBN}$ ). (B) High magnification image of the circled portion from Figure (A) showing

2 a ruptured lysosome (ruptured portion depicted with arrows). (C) Alveolar macrophage

3 from BALF of C57BL/6 mice exposed to BNNT-M (40 mg) for $24 \mathrm{~h}$. (D) High

4 magnification image of the circled portion from Figure (C) showing a ruptured lysosome

5 (ruptured portion highlighted with arrows). (E) Pretreatment with acridine orange

6 followed by challenge with BNNT-M showed 20-fold increase in green fluorescence

7 suggesting lysosomal membrane permeabilization. Reprinted with permission. [186]

8 Copyright 2017, Informa UK Limited.

9

10 Figure 9. Cytokine secretion of different macrophages. Macrophage-like THP-1 cells 11 were treated with $50 \mu \mathrm{g} / \mathrm{mL}$ of BP and an increasing concentration of corona complexes $12(12.5,25$ and $50 \mu \mathrm{g} / \mathrm{mL})$ for $6 \mathrm{~h}$. Values are expressed as the means \pm SDs of triplicates. 13 Statistical significance is assessed by Student's t test. ${ }^{*} \mathrm{p}<0.05,{ }^{*} \mathrm{p}<0.01$. Reprinted 14 with permission. ${ }^{[202]}$ Copyright 2018, Springer Nature.

16 Figure 10. RAW 264.7 cells engulf tungstate nanospheres. TEM analysis of RAW 264.7

17 cells exposed to tungstate nanospheres for $3 \mathrm{~h}$. Reprinted with permission. ${ }^{[219]}$ Copyright 18 2014, Informa UK Limited.

19

20 Figure 11. Macrophages and 2D materials mainly result in inflammation. 